\title{
جريمة الاختفاء القسري \\ دراسة تحليلية في المواثيق الدولية
}

Doi: 10.23918/ilic2021.25

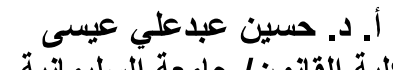

كلية القانون/ جامعة السليماتية

husseinissa@hotmail.com

\section{المقدمة}

عانت بلدان أمريكا اللاتينية، وبخاصة منها (غواتيمالا، السلفادور، الأرجنتين، البرازيل، هوندور اس، بوليفيا، المكسيك، هايتي)،

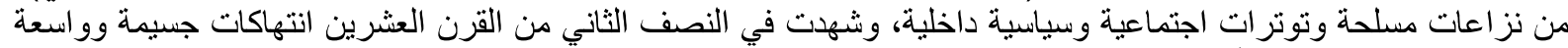

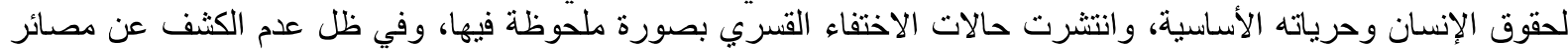

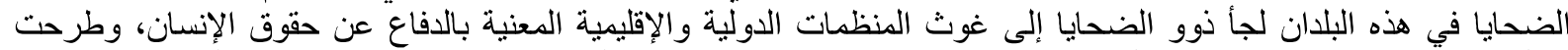

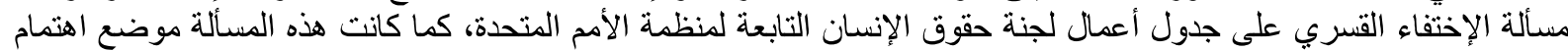

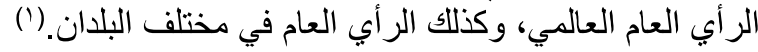

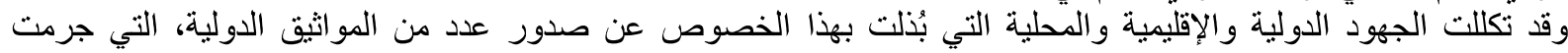

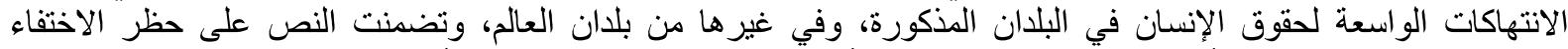

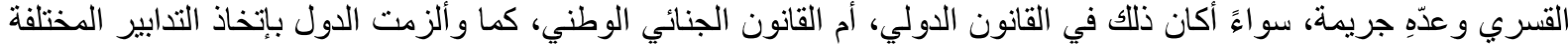
للتصدي له، والعمل على ضمان حقوق الضحايا، ودعاقبة الجناة.

وتمثلت أبرز هذه المواثيق الدولية بصورة خاصة في إعلان حماية جميع الأشخاص من الاختفاء القسري لعام ب99 19، والإتفاقية

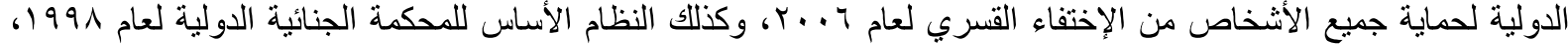

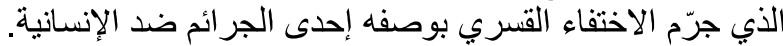

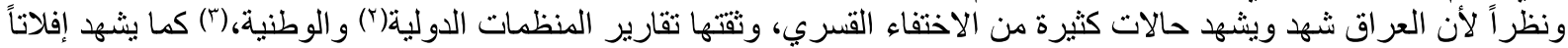

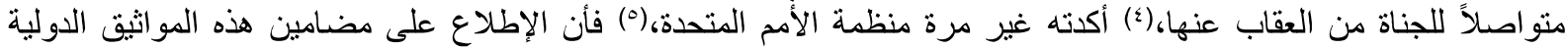
يكتسب أهمية كبيرة على صعيد التصدي لهذه الجريمة بصفة عامة، والاستناد إليها في تجريمها والعقاب عليها في التهاب التشريع العقابي الإني العراقي بصفة خاصة، والاستفادة مما يتمخض عن العن هذا البحث من توصيات في إغناء وتطوير (مشروع قانون مكافحة الاختفاء

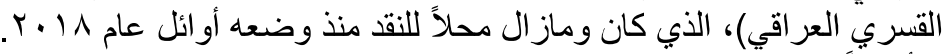

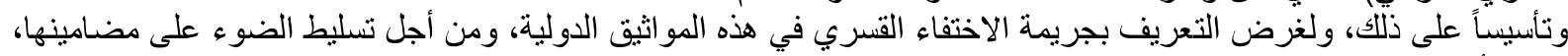

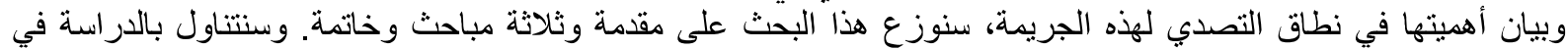
المبحث الأول إعلان حماية جميع الأشخاص من الاختية الأفاء القسري، وفي المبحث الثاني النظام الأساس للمحكمة الجنائية الدولية، وفي المبحث الثالث إتفاقية حماية جميع الأشخاص من الاختفاء القسري. وسندرج في خاتمته الاستنتاجات والتوصيات الرئيسة

\section{المبحث الأول}

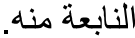

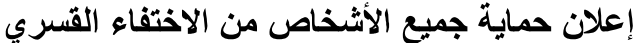

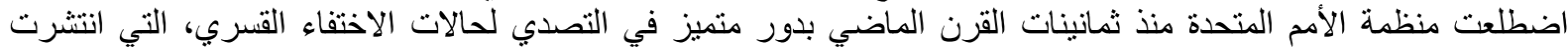

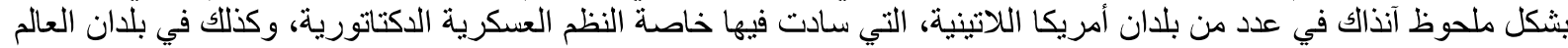

(1) رنا سلام أمانة، قيصر عادل عاد عبدالدين، الاختفاء القسري و أثره على حق الإنسان في الحياة، المجلة الأكاديمية العالمية للدراسات القانونية، المجلد (Y)، http://iajour.com/index.php//r/article/view/71

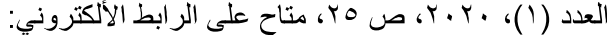

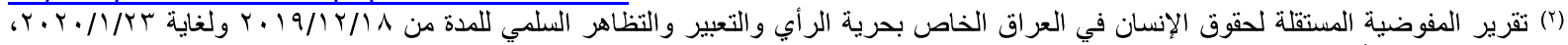
http://ihchr.iq/upload/upfile/ar/124.pdf متاح على الر ابط الألكتروني:

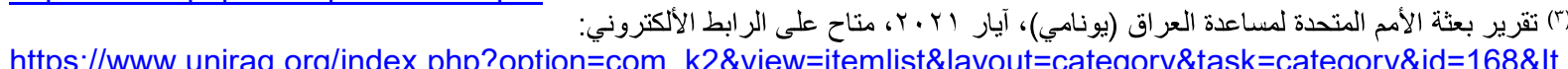
emid=644\&lang=ar

https://www.hrw.org/ar/news/2020/05/18/375158

$$
\text { تقرير (منظمة مر اقبة حقوق الإنسان)، آيار .r.r، متاح على الر ابط الألكتروني: }
$$

(أ) حسين عبدعلي عيسى، حالات الاختفاء القسري في العراق وإنإنكاليات المواجهة من المنظورين السياسي والقانوني، المجلة الأمريكية الدولية للعلوم http://www.aijhssa.us/2021/05/19/

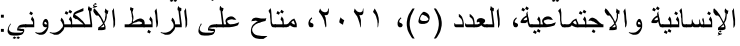

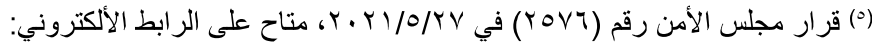
https://www.un.org/securitycouncil/ar/content/resolutions-adopted-security-council-2021 


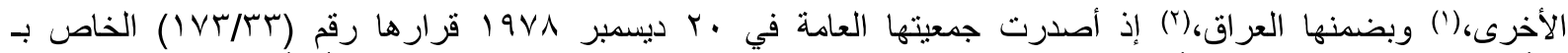

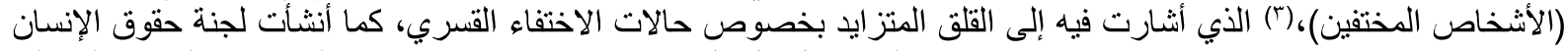

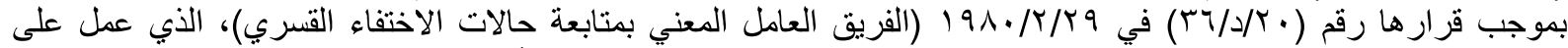

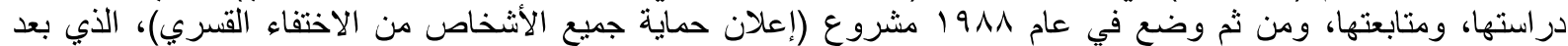

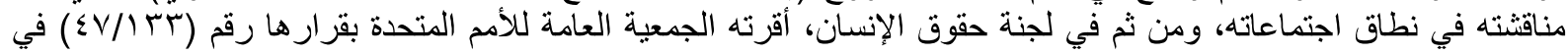

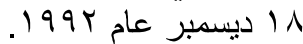

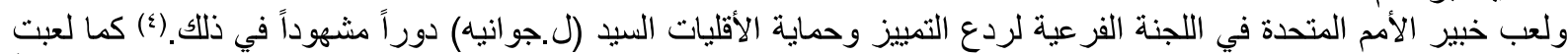

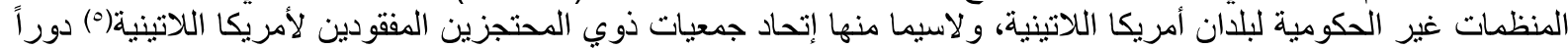

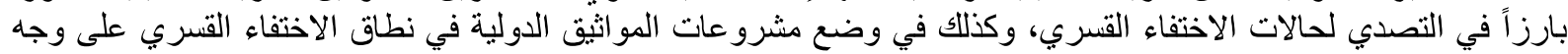

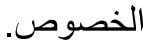

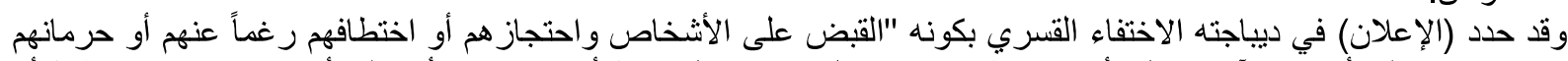

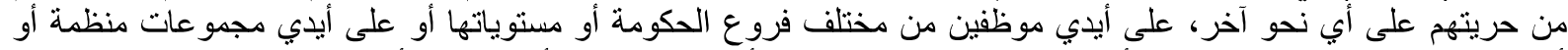

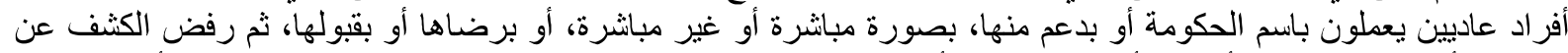

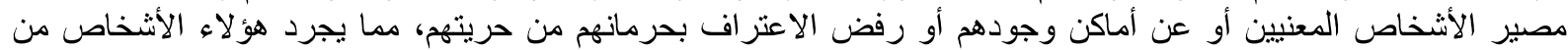

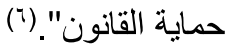

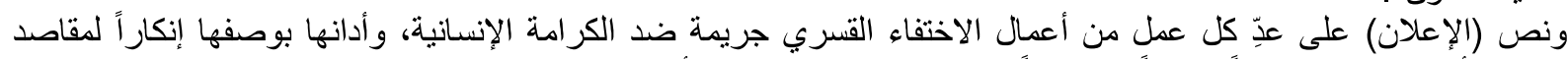

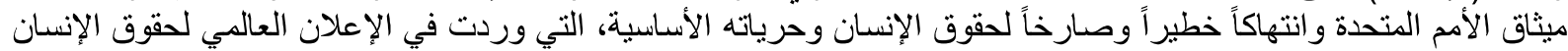

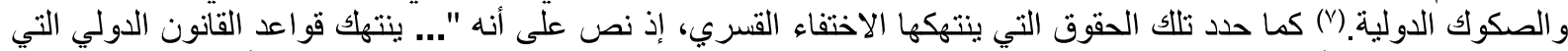

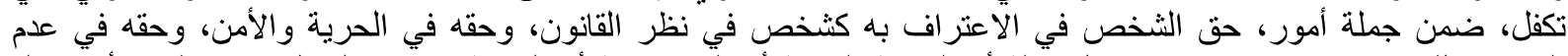

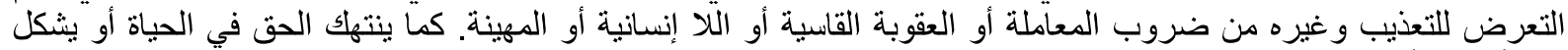

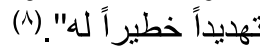

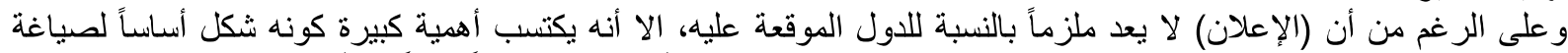

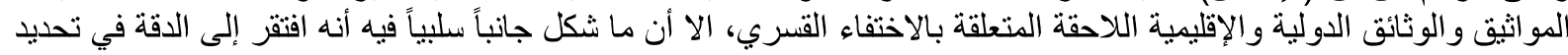

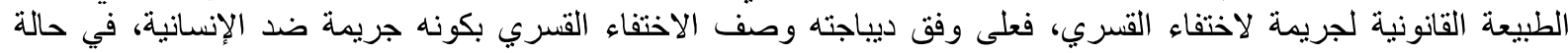

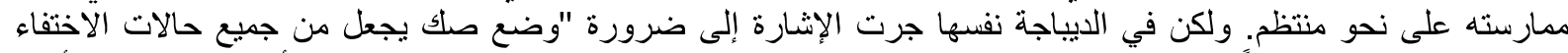

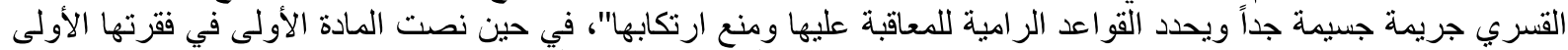

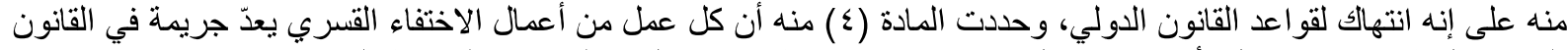

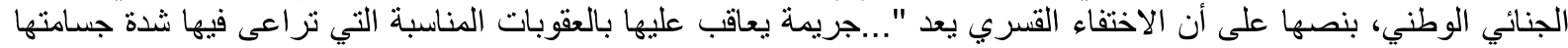

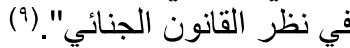
وبموجب (الإعلان) يعدّ الاختفاء القسري جريمة مستمرة باستمرار مرتكبيها في التكتم على مصير الضيد الضحية ومكان إخفائها،

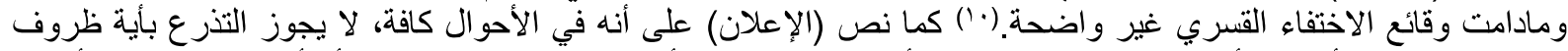

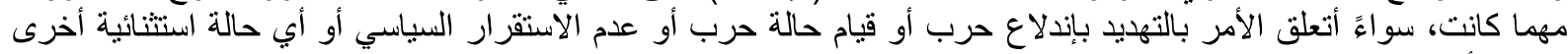

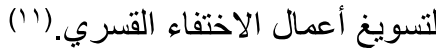
وكفلت أحكام (الإعلان) حقوق الضحايا في المعاملة الإنسانية في مرحلة حرمانهم من حريتهم، وفي الحفاظ على سلامتهم البدنية،

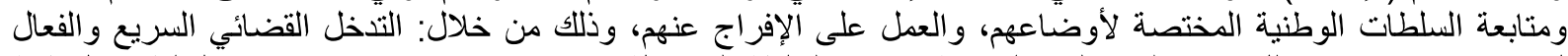
لتحديد مكان وجودهم وللوقوف على حالتهم الصحية وتحديد السلطة المسؤولة عن حرمانهم من حريتهم، ومنح السلطات الونات الوطنية

(') نومان حمود مضحي، الاحتجاز القسري في منظور القانون الدولي العام، مجلة العلوم القانونية والسياسية، كلية القانون والعلوم السياسية، جامعة ديالى،

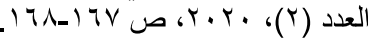
() (؟) عماد كاظم الثلبي، الواقع التطبيقي للانتهاكات الجسيمة الماسة بحقوق الإنسان، العراق أنموذجاً، مجلة مركز دراسات الكوفة، جامعة الكوفة، العدد

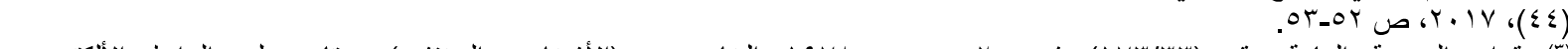

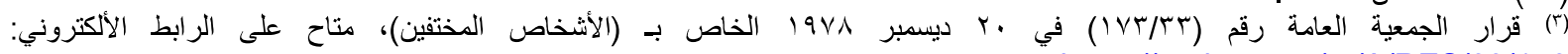

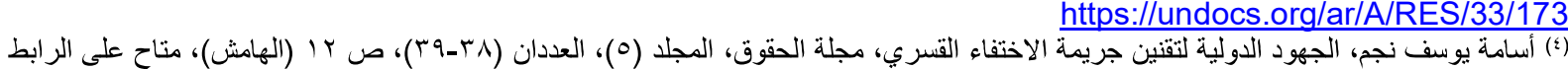

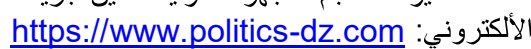

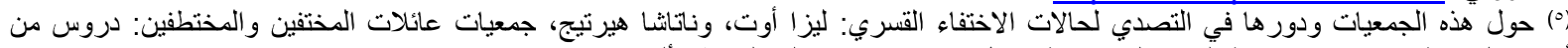
https://www.swisspeace.ch/about-us/staff/lisa-ott

(1) إعلان حماية جميع الأشخاص من الاختفاء القسري لعام ب991931، متاح على الر ابط الألكتزوني: https://www.un.org/ga/search/view doc.asp?symbol=A/RES/47/133\&Lang=A

$$
\begin{aligned}
& \text { (1) الفقرة (1) من المادة (1) من الإعلان. }
\end{aligned}
$$

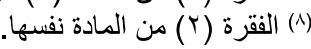

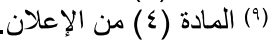

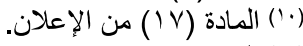

$$
\begin{aligned}
& \text { (") المادة (V) من الإعلان. }
\end{aligned}
$$




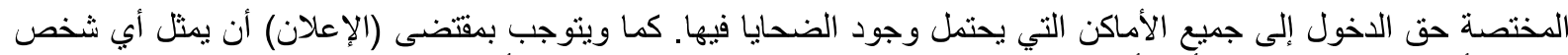

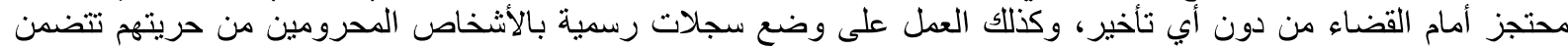

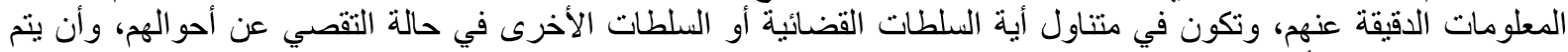

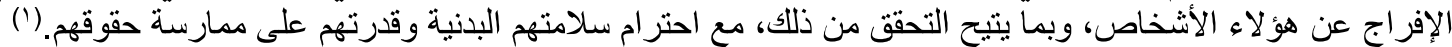

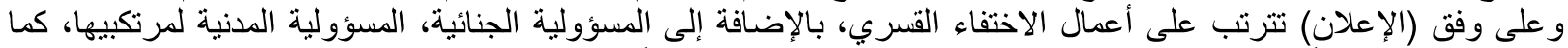

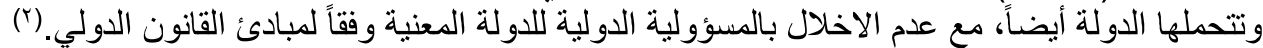

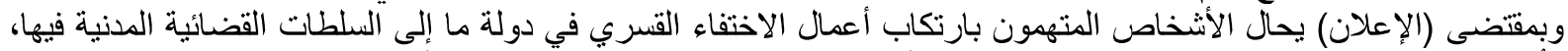

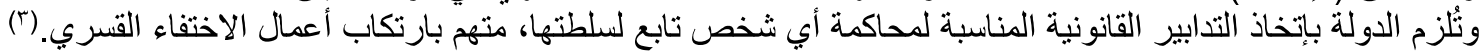

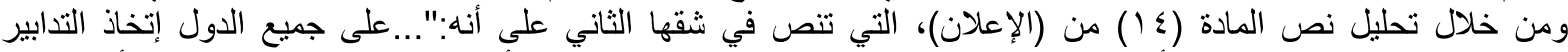

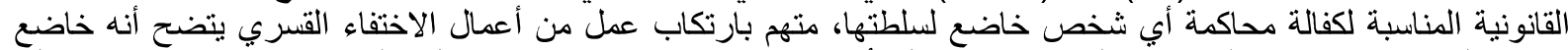

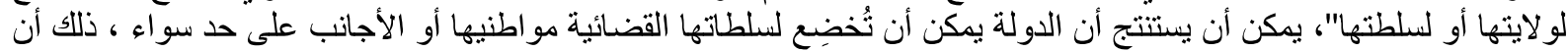

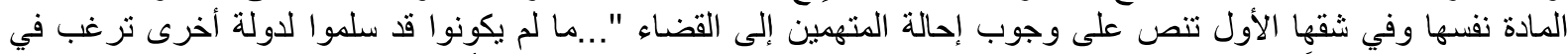

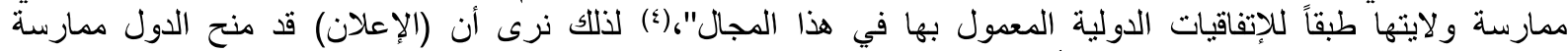

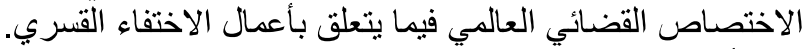

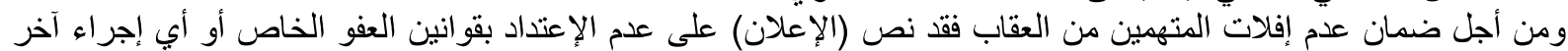

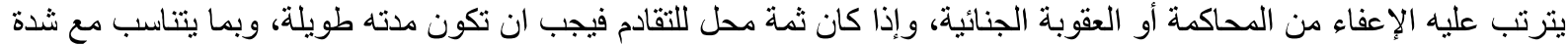

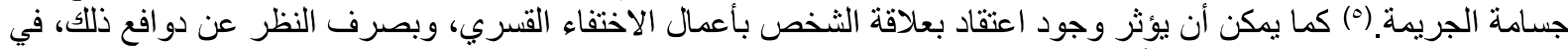

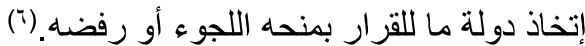

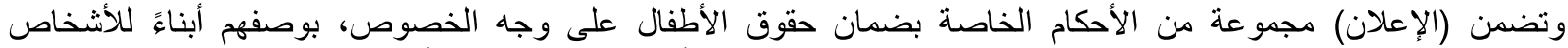

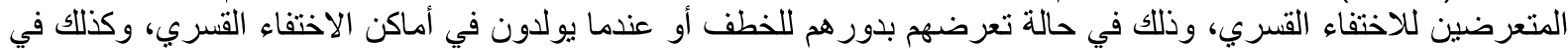

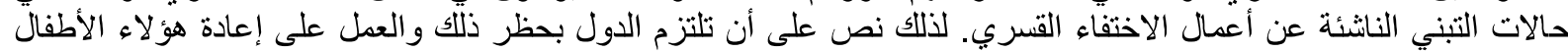

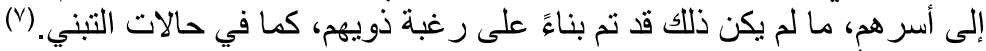

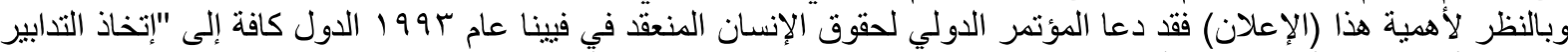

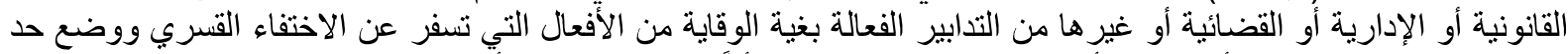

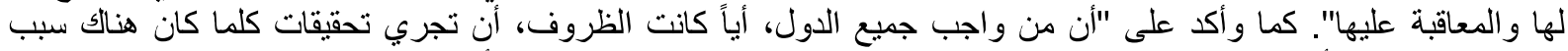

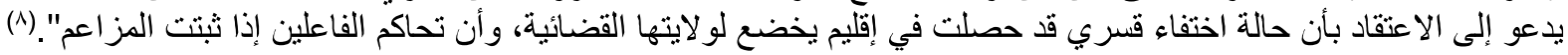

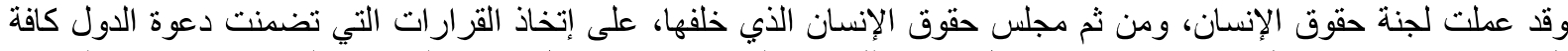

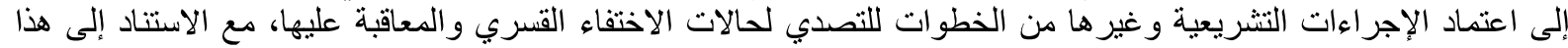

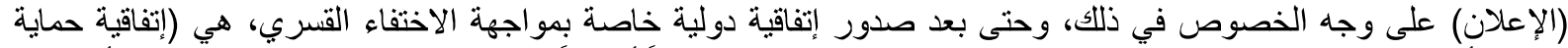

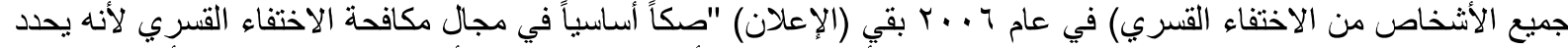

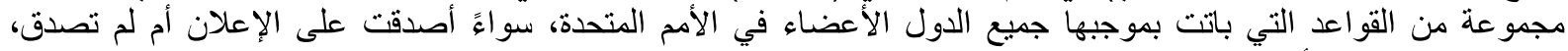

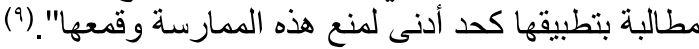

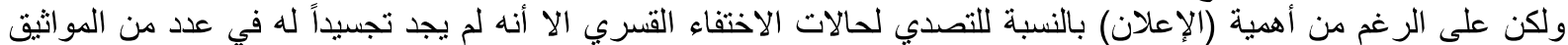

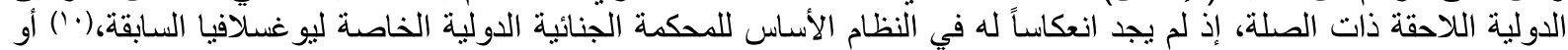

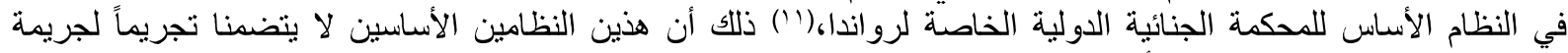

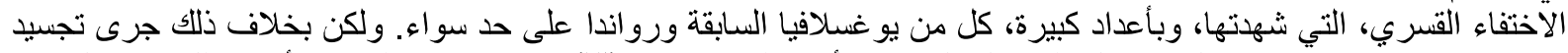
مضمونه في مشروع مدونة الجرائم المخلة بسلم البشرية وأمنها لعام 1997 .(r') كما وتضمن النظام الأساس للمحكمة الجنائية

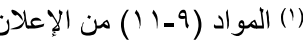

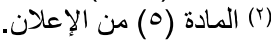

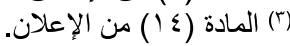

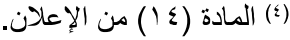

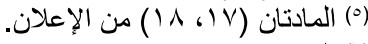

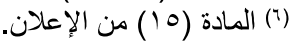

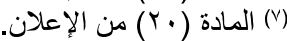

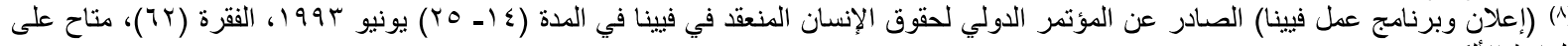
https://www.ohchr.org/AR/Professionallnterest/Pages/Vienna.aspx الرابط الألكتروني: (9) حالات الاختفاء القسري أو غير الطوعي، مفوضية الأمم المتحدة السامية لحقوق الإنسان، جنيف، 9. . T، ص آ، متاح على الر ابط الأكتروني: https://www.ohchr.org/Documents/Publications/FS6 rev.3 Disappearances ar.pdf https://www.icty.org/en/documents/statute-tribunal (·) النظام الأساس للمحكمة الجنائية الدولية الخاصة ليو غسلافيا السابقة، متاح على الر ابط الألكتروني. (') النظام الأساس للمحكمة الجنائية الدولية الخاصة لرواندا ، متاح على الر ابط الألكتروني: https://unictr.irmct.org/sites/unictr.org/files/legal-library/100131 Statute en fr 0.pdf (r) (r) مشروع مدونة الجر ائم المخلة بسلم البشرية وأمنها لعام 1997 ، متاح على الر ابط الأكتروني: 


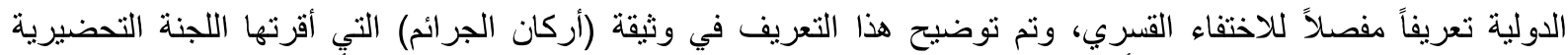
للاحكمة عام r. . r،(() التي على أساسها حددت عناصر جريمة الاختفاء القسري بالاستناد إلى الأحكام الرئيسة التي تضمنها

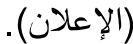

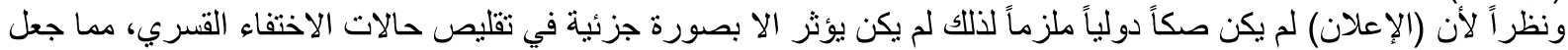

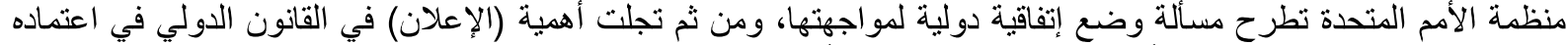

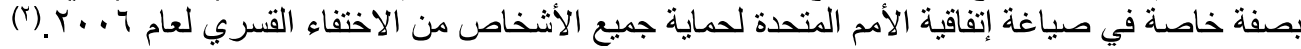

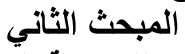

\section{النظام الأساس للمحكمة الجنائية الاولية}

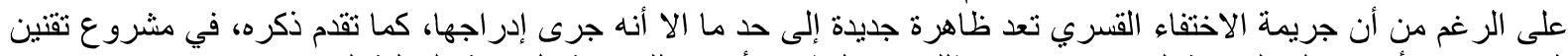

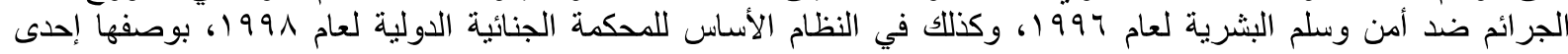

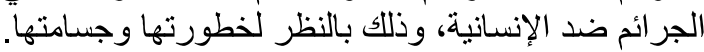

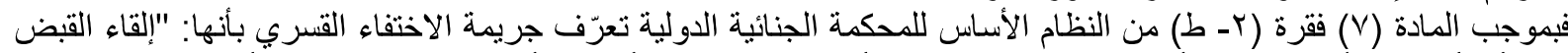

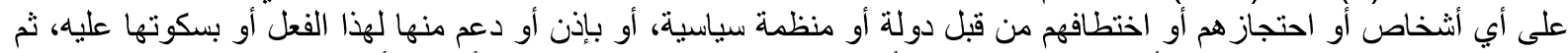

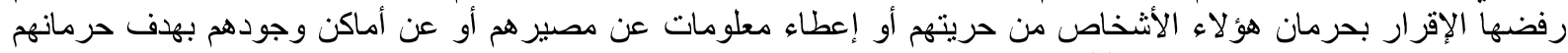

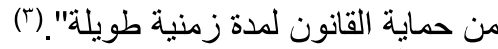

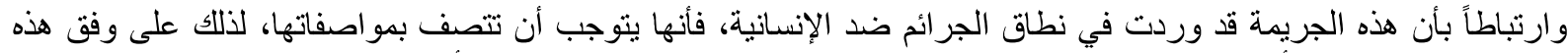

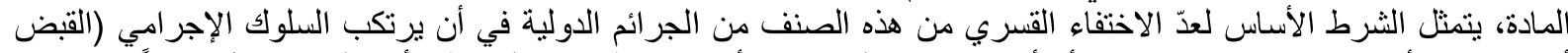

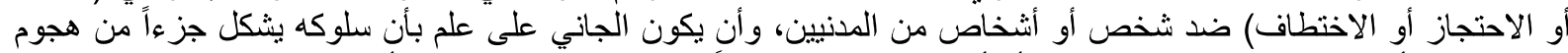

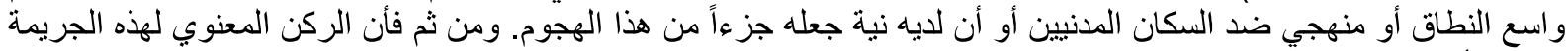

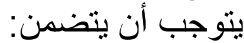
أولاً: إن إلقاء القبض علضّ على الثخص أو الأشخاص أو احتجازهم أو اختطافهم سيليه في سير الأحداث العادية رفض الإقرار

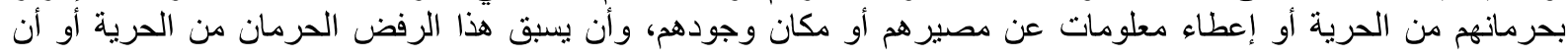

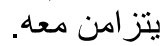

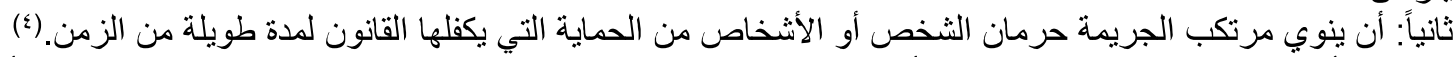

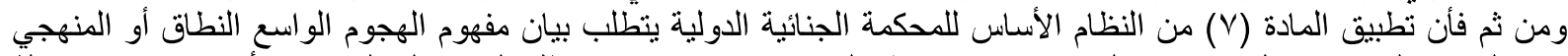

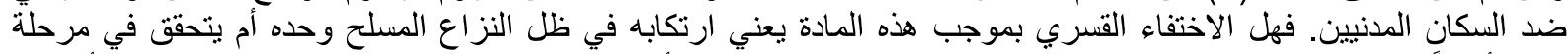

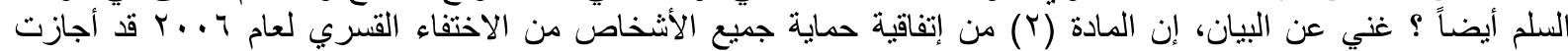

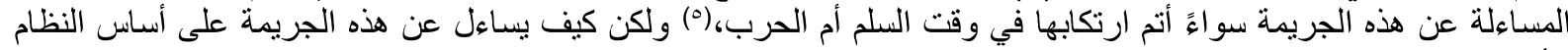

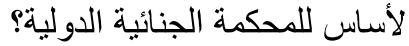

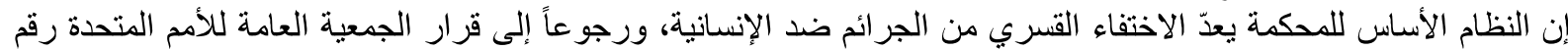

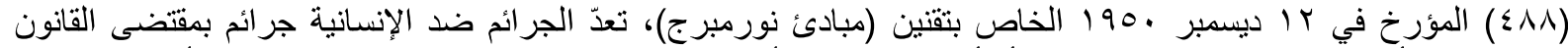

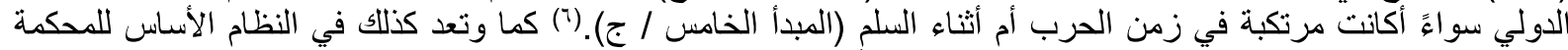

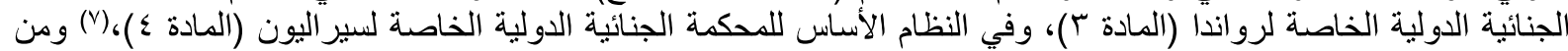

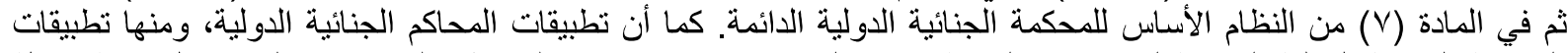

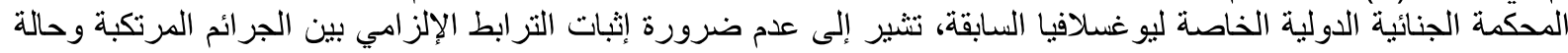

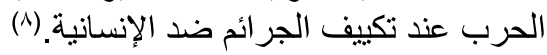

https://undocs.org/pdf?symbol=ar/A/72/10

http://hrlibrary.umn.edu/arab/iccelements.html

(1) (المكمة الجنائية الدولية ، أركان الجر ائم ، متاح على الرابط الألكتروني:

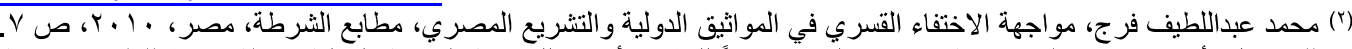
(r) (للتفاصيل: أحمد تقي فضيل، جريمة الاختفاء القسري وفقاً للنظام الأساس للمحكمة الجنائية الدولية، مجلة واسط للعلوم الإنسانية، جامعة واسط، العدد

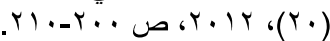

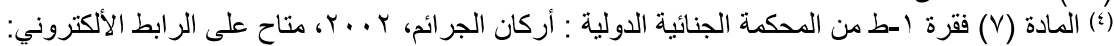
http://hrlibrary.umn.edu/arab/iccelements.html https://www.ohchr.org/ar/hrbodies/ced/pages/conventionced.aspx

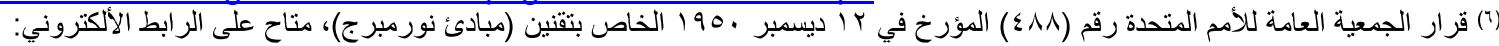
https://research.un.org/en/docs/ga/quick/regular/5

(v) النظام الأساس للمحكمة الجنائية الدولية الخاصة لسير اليون، متاح على الرابط الألكتروني: http://rscsl.org/Documents/RSCSL\%20Agreement\%20and\%20Statute.pdf

(8) Prosecutor $\vee$ D. Tadic, case No. IT-94-1-Tk opinion and Judgment, 7 may 1997, Par.141, Prosecutor v. Blaskis, Case No. IT-95-14-T, Judgment, 3 March 2000, International Criminal Tribunal for the Former Yugoslavia, Par.66-68. 


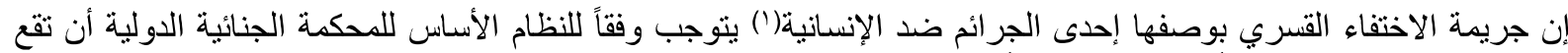

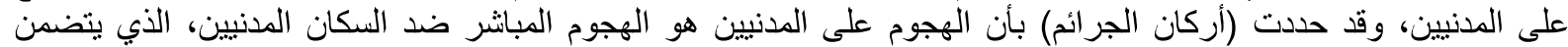

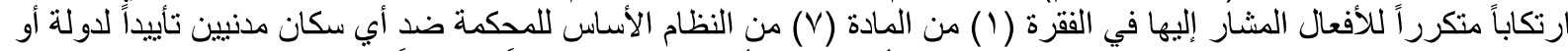

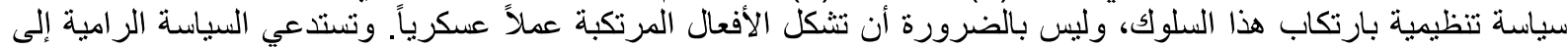

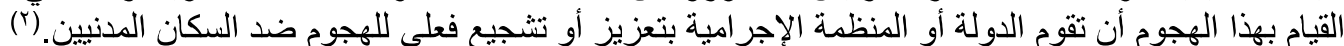

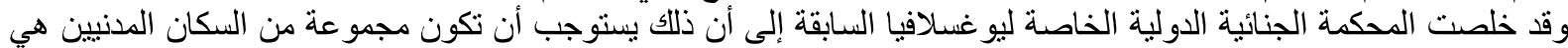

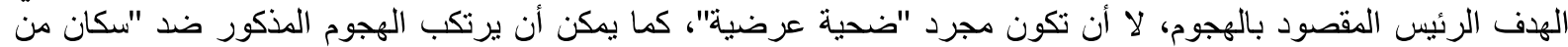

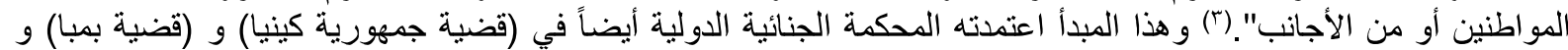

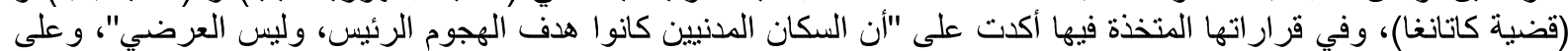

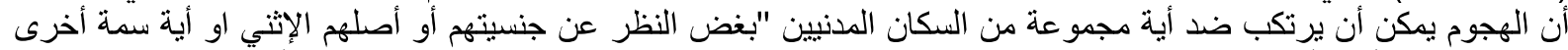

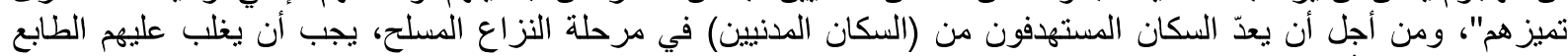

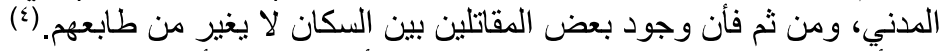

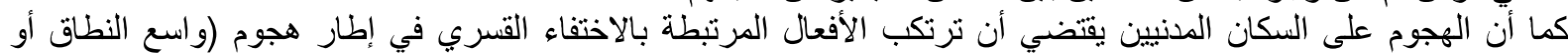

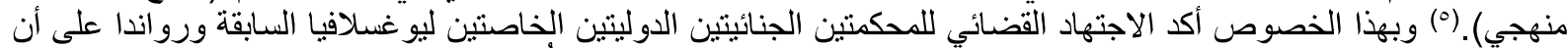

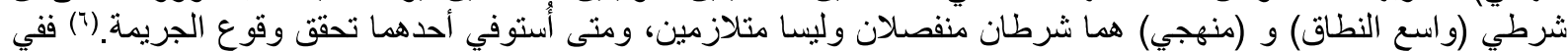

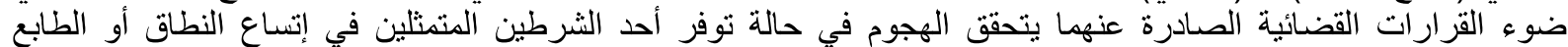

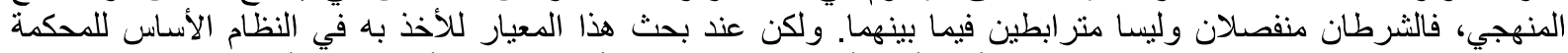

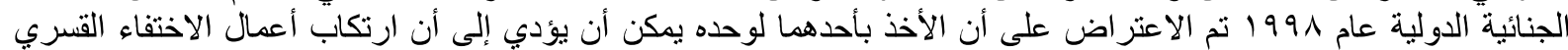

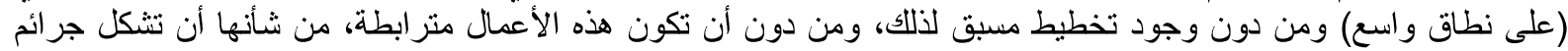

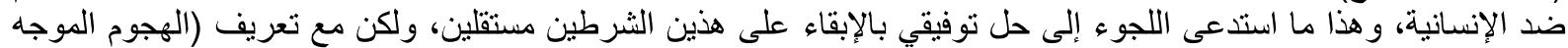

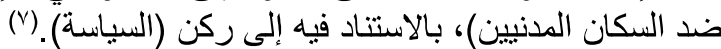

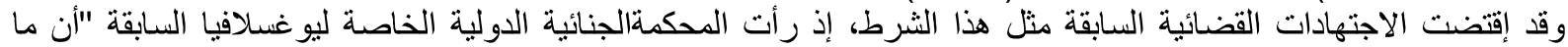

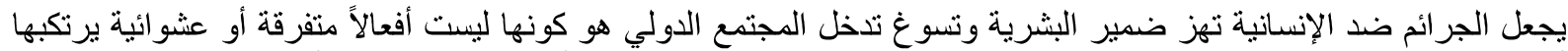

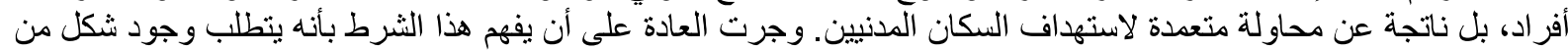

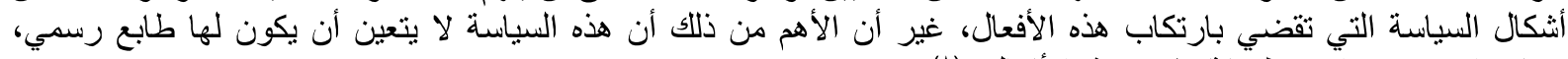

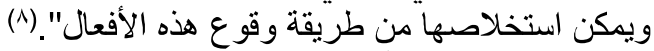

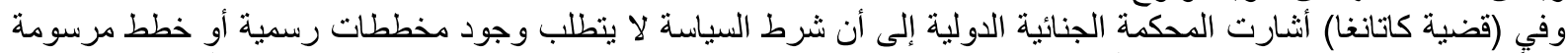

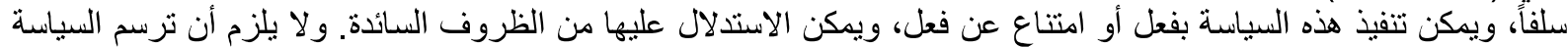

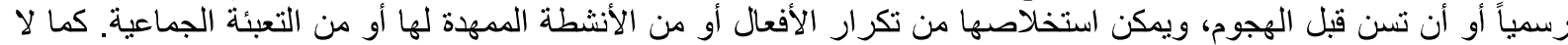

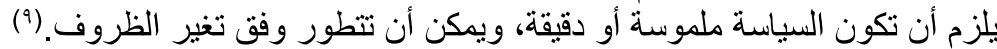

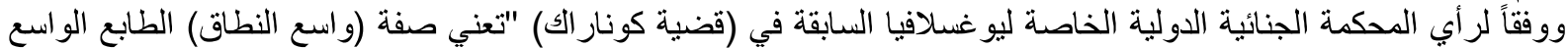

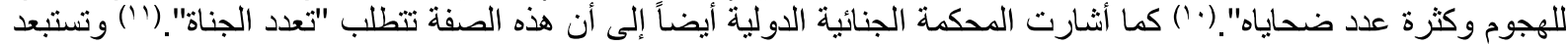

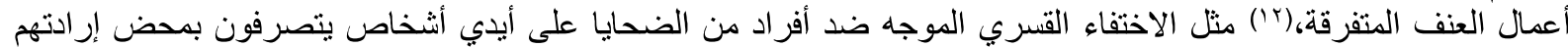

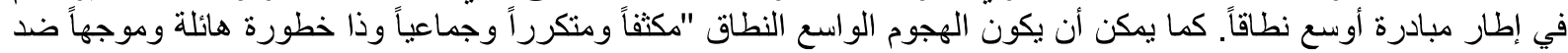

(1) للتفاصيل حول أركان جريمة الاختفاء القسري في النظام الأساس للمحكمة الجنائية الدولية ينظر : جواد كاظم طراد الصناد الصريفي، الجرائم ضد الإنسانية في

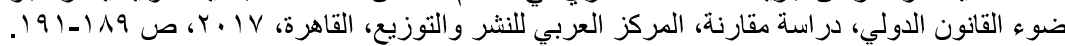

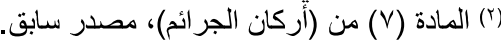

(3) Kunarac, case No. IT-96-23-T \& IT-96-23-1, Judgment, 22 february 2001, Par.421, 424.

(4) Situation in Republic of Kenya, Case No.ICC-01-09, Decision, 31 march 2010,Bemba ,Case No.ICC01/2/05-01/08, Decision, 15 june 2009, Par.76, Katanga, Judgment, Case No.ICC-01/04-01/07, 7 march 2014, Par.1104, 1105

(o) بتفصيل أكبر حولهما: مازن خلف ناصر، الحماية الجنائية للأشخاص من الاختفاء القسري، دراسة مقارنة، أطروحة دكتور اه، كلية القانون، جامعة بابل،

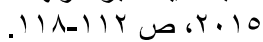

(6) Prosecutor v. Mille Mrksic, Miroslac Radic and Veselin Sljivancanin, International Criminal Tribunal for the former Yugoslavia,Par. 437. 27-9-2007, Prosecutor v. Clemen Kayishema and Obed Ruzindana, International Criminal Tribunal for Rwanda, Par. 123. 21-5-1999.

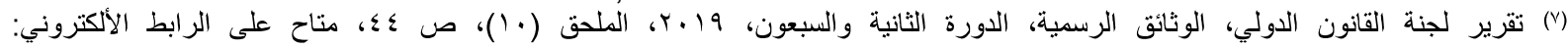

(8)Prosecutor v D. Tadic, مصدر سابق, Par.653.

https://undocs.org/pdf?symbol=ar/A/72/10

(9) Katanga, مصدر سابق, Par. 1108-1110,1113.

(10) Prosector v Kunarac, مصدر سابق, Par.163.

(11) Prosector v. Bemba, مصدر سابق, 15 June 2009, Par. 83.

(12) Prosector V.Ntaganda, case No.ICC-01/04-02/06, Decision, 13 july 2012, Par.19. 
ضحايا متعددين".(') وفي الوقت نفسه، يمكن أن يشكل فعل منفرد يقوم به أحد الجناة جريمة ضد الإنسانية إذاذا حدث في سياق

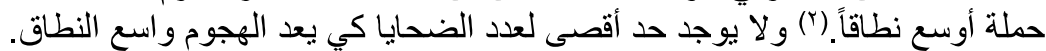

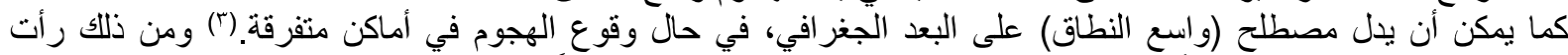

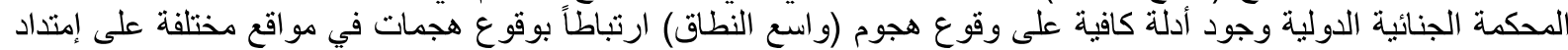

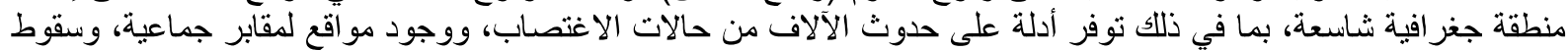

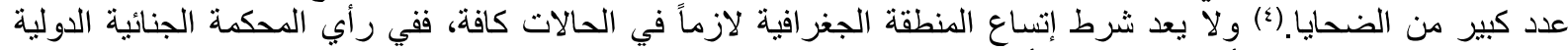

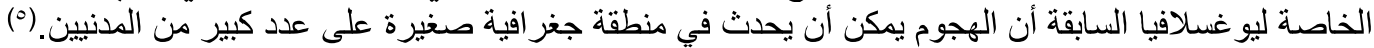

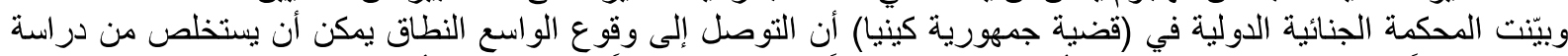

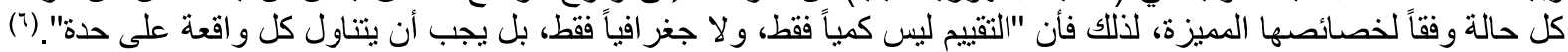

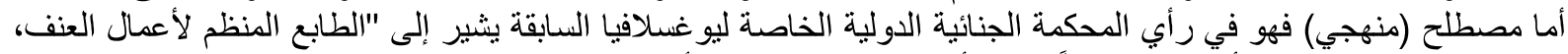

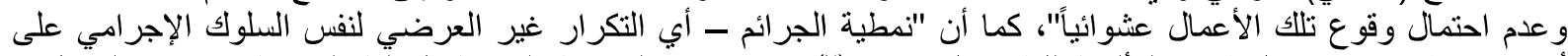

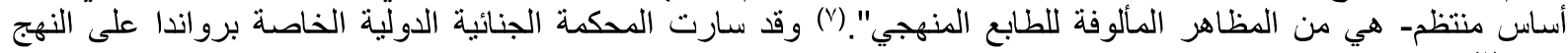

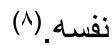

كما رأت المحكمة الجنائية الدولية في (قضية هارون) أن عبارة (منهجي) تشير إلى "الطابع المنظم لأعمال العنف و عدم احتمال

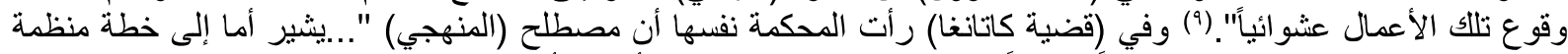

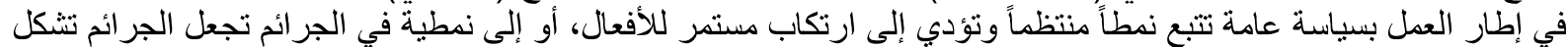

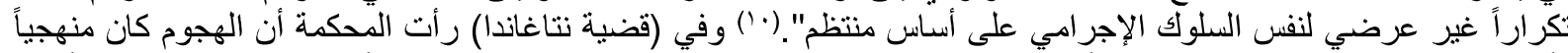

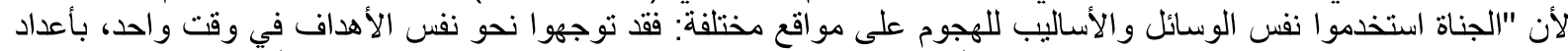

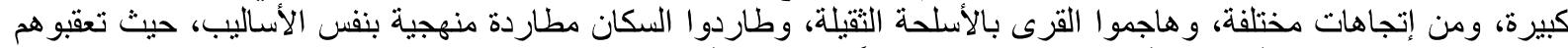

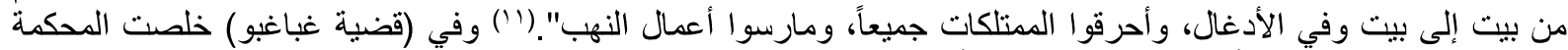

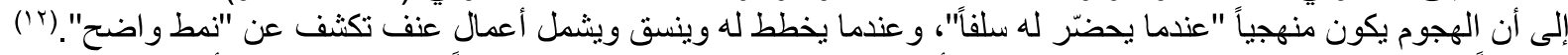

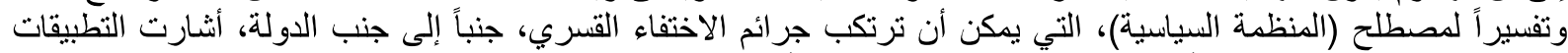

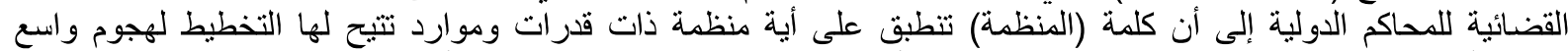

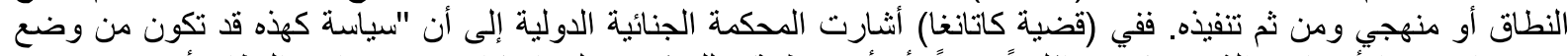

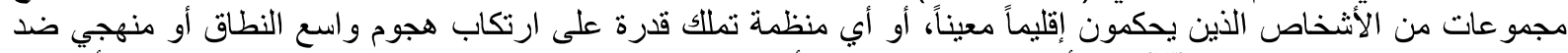

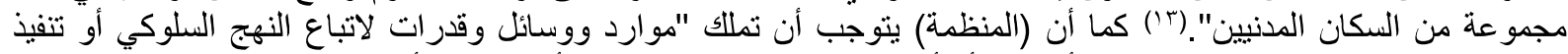

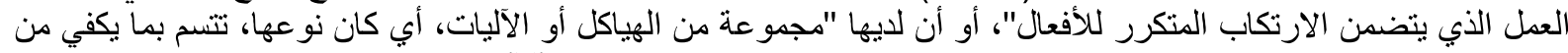

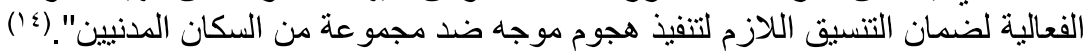

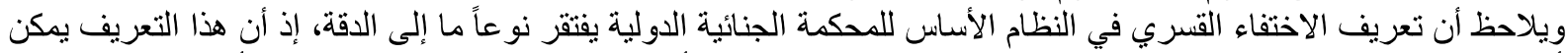

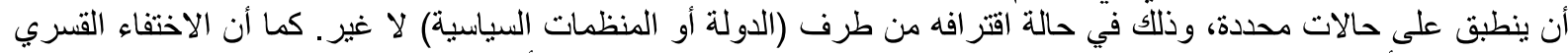

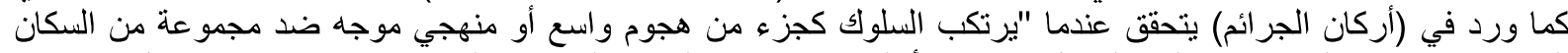

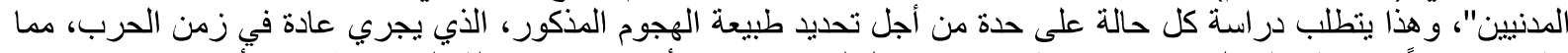

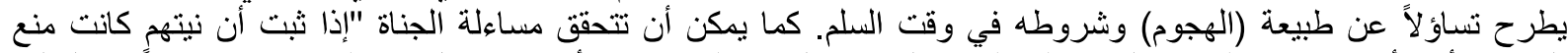

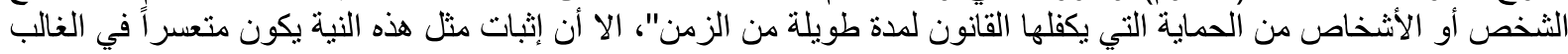

\section{المبحث الثالث}

على الصعيد التطبيقي.

\section{إتفاقية حماية جميع الأثخاص من الاختفاء القاء القسري}

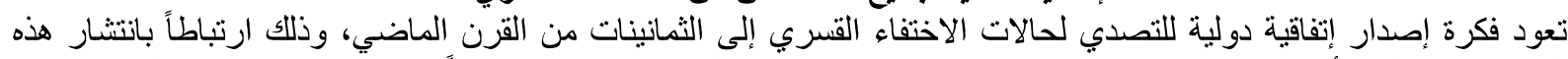

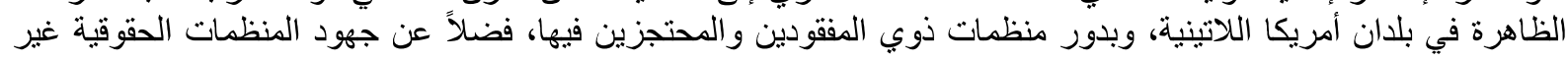

(1) Prosector v. Bemba, مصدر سابق, 21 March 2016, Par. 163.

(2) Prosector v D. Tadic, مصدر سابق, Par.649.

(3) (3) Prosector V.Ntaganda, مصدر سابق, Par. 30.

(4) (4) Prosector v. Bemba, 21 March 2016, Par. 688-689.

(5) Prosecutor v. Blaskis, مصدر سابق, Par. 206.

(6) Situation in Republic of Kenya, مصدر سابق, Par.95.

(7) Prosector v Kunarac, 22 february 2001, مصدر سابق سابق, Par.429, 12 june 2002, Par. 94.

(8) Kayishema, Judgment, 21 May 1999, Par.123M, Akayesu, Judgment, 2 September 1998, Par.580.

(9)Prosector v. Harun, Case No. ICC-02/05-01/07, Decision, 27 April 2007, Par. 62.

(10) Prosector v. Katanga, Decision, 30 September 2008, Par. 397.

(11) Prosector v. Ntaganda, Decision, 13 July 2012, Par. 31.

(12) Prosecutor v. Laurent Gbagbo, Case No. ICC-02/11-01/11, Decision, 12 June 2014, Par. 225.

(13) Prosector v. Katanga, Decision, 30 September 2008, Par. 396.

(14)Prosector v. Katanga, Decision, 7 March 2014, Par. 1119. 


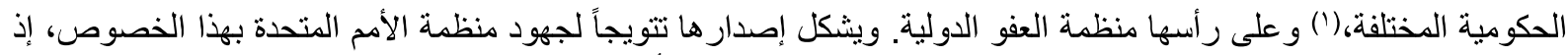

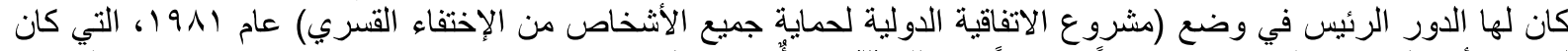

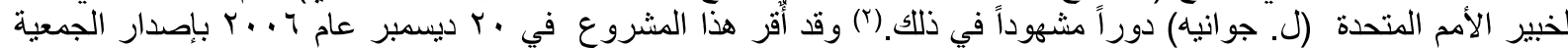

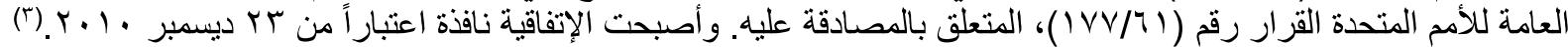

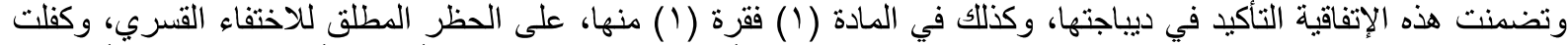

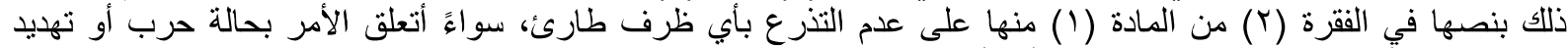

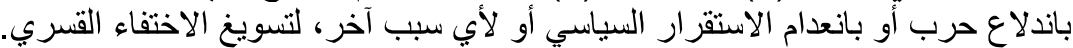

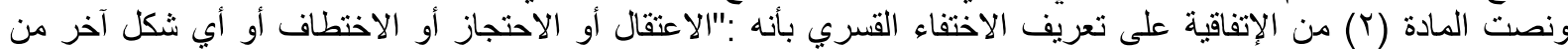

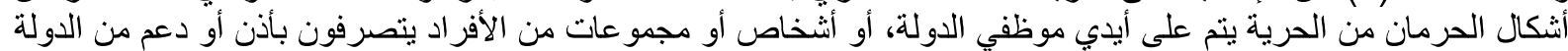

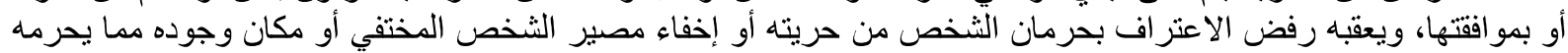
من حماية القانون".

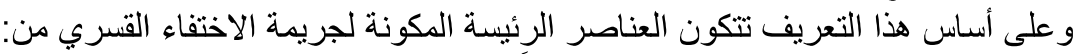

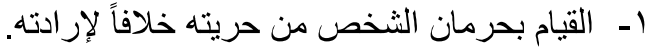

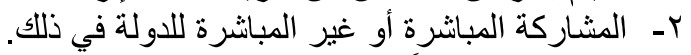

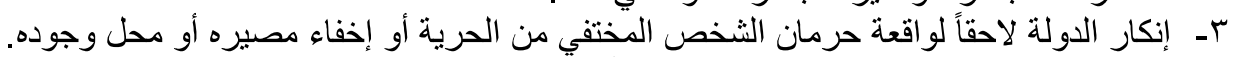

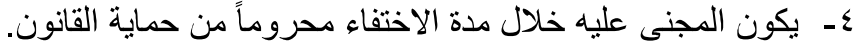

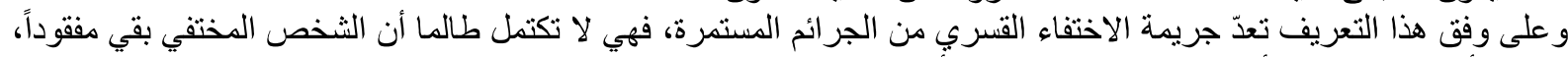

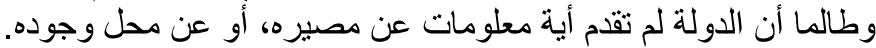

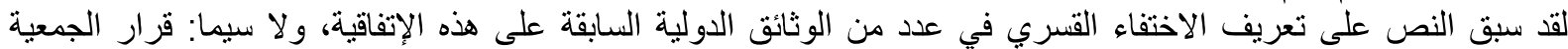

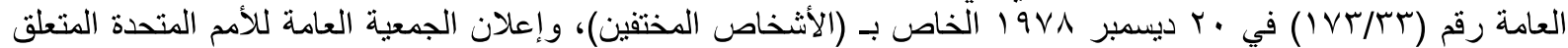

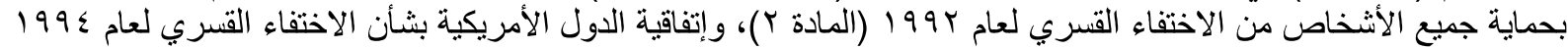

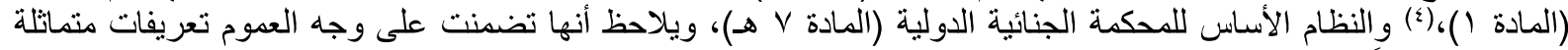

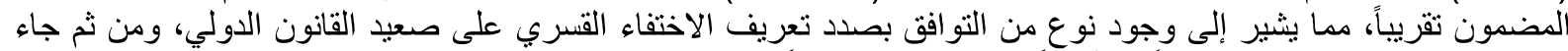

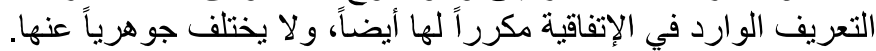

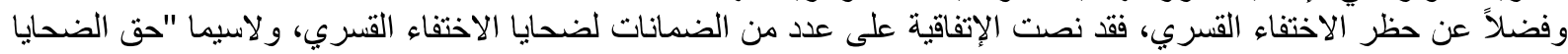

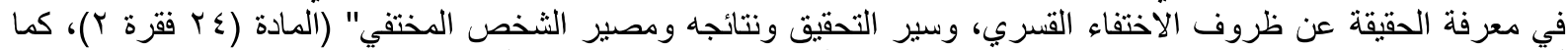

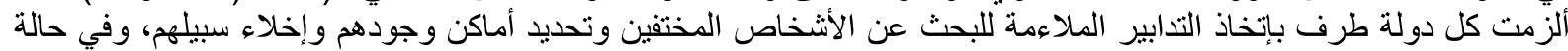

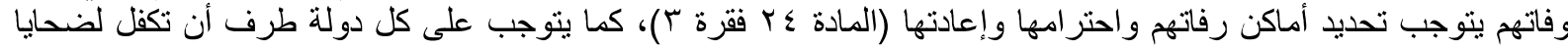

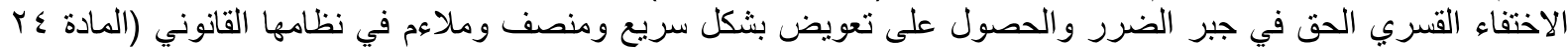

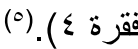

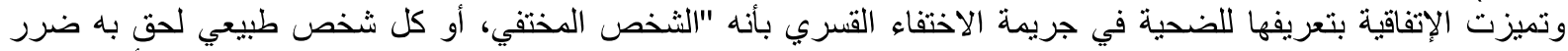

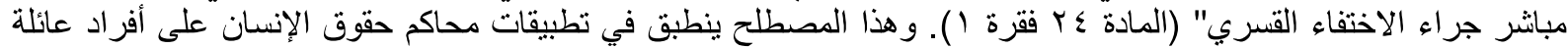

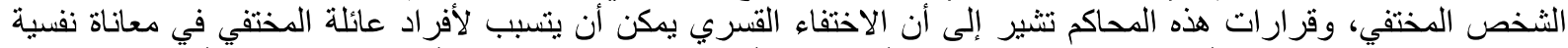

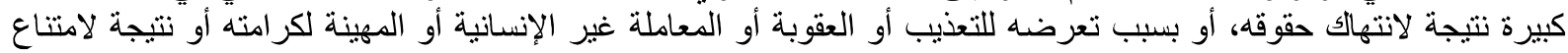

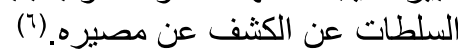

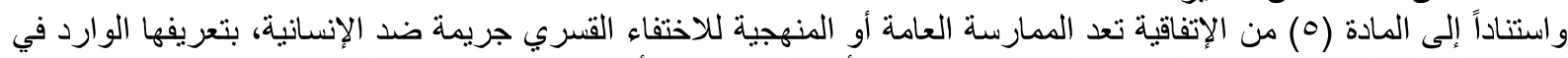

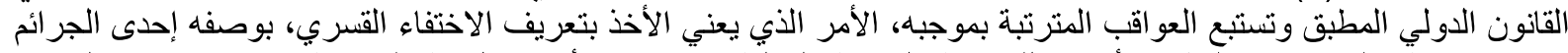

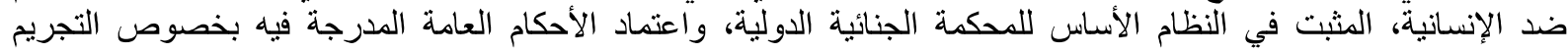

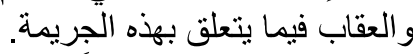

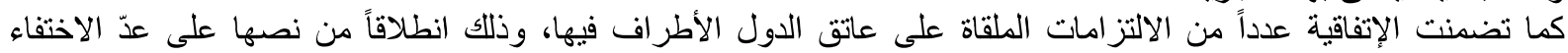

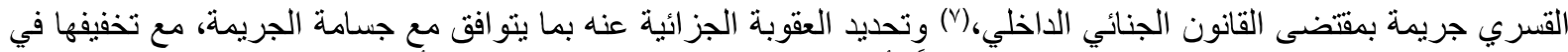
حالة مساهمة الجاني في إعادة الثخص المختفي حياً، أو في الكثف عن ملابسات اختفائه، أو في تحديد هوية المسؤولين عن فئن

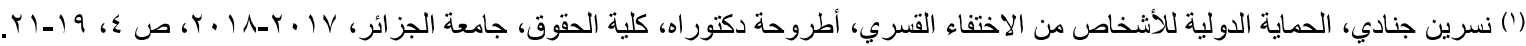

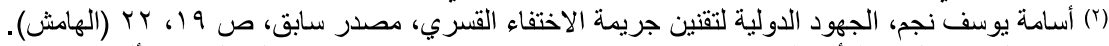

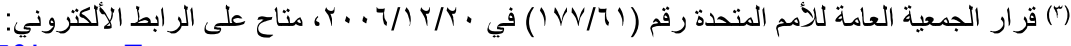
https://undocs.org/ar/A/RES/61/177\&Lang=E http://www.oas.org/juridico/english/treaties/a-60.html

() إتفاقية الدول الأمريكية بشأن الاختفاء القسري لعام ع99 19، متاح على الر ابط الألكتروني:

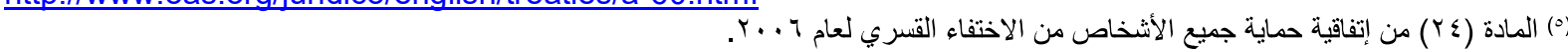
(6) ECtHR, Ashlakhanova v Russia, 18 December 2012, Orhan v Turkey, 18 June 2002UN Human Rights Committee, Celis Laureano v. Peru, Communication 540/1993, Views, 25 March 1996, para. 8.5, Mojica v Dominican Republic, Communication 449/1991, para. 5.7.

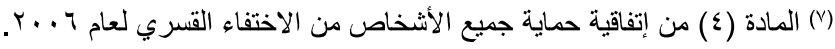




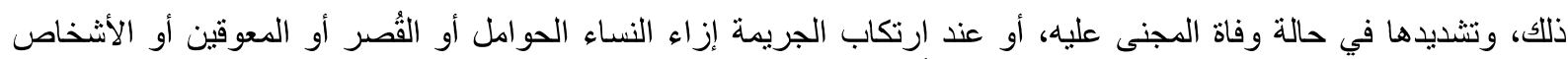

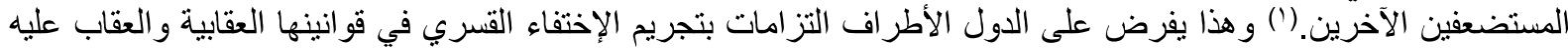

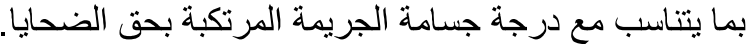
كما احتوت الإتفاقية عدداً من الأحكام المتعلقة بالمساءلة الجزائية عن الجرائة الجريمة، سواءً أكان ارتكاب الجاني الجرئة الجريمة بصورة

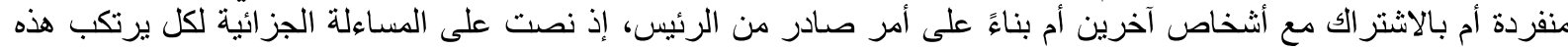

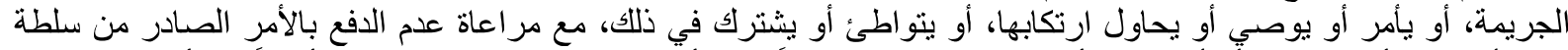

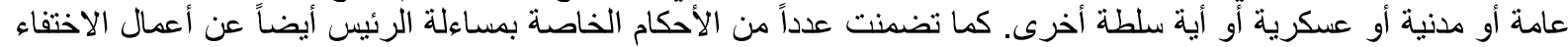

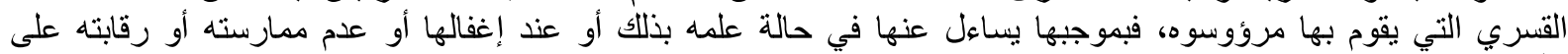

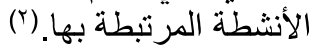

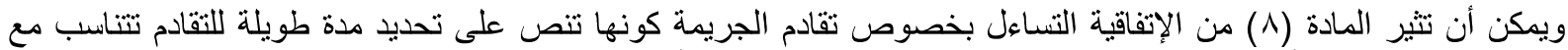

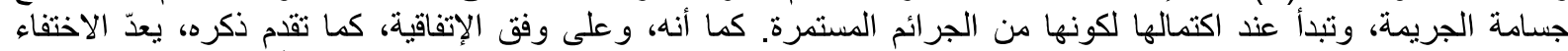

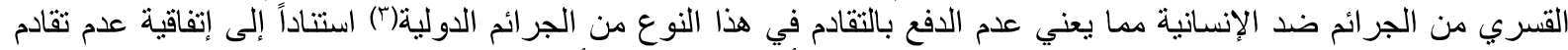

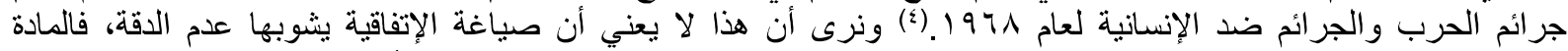

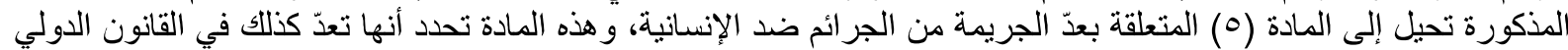

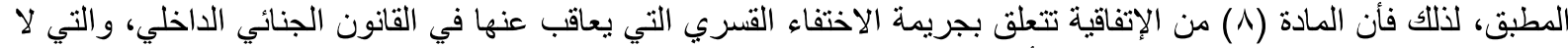

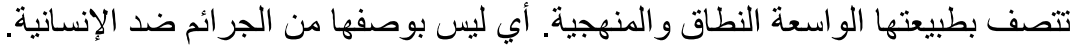

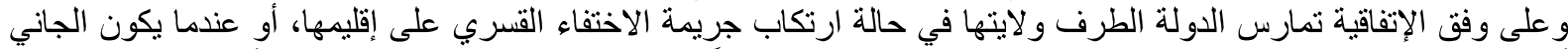

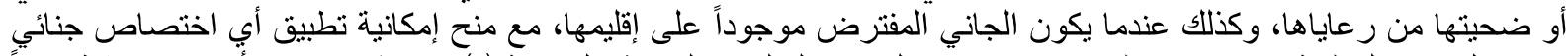

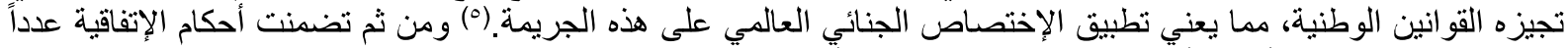

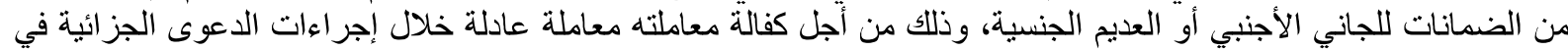

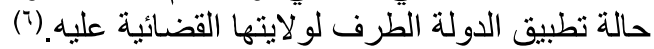

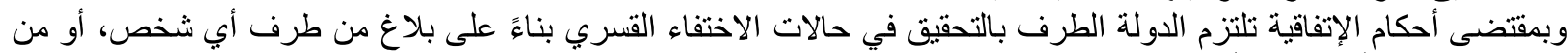

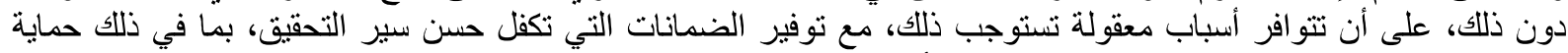

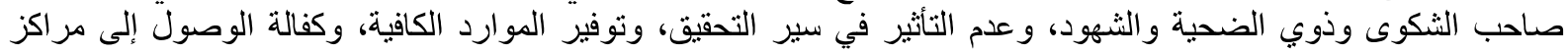

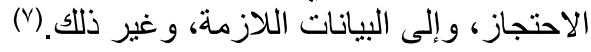

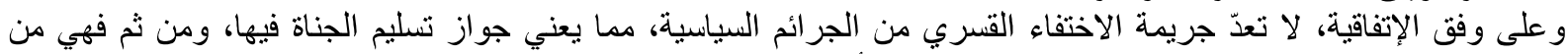
الجرائم الموجبة للتسليم. وفي هذه الحالة تكون الاتفاقية الأساس القانوني للتسليم في حالات الاختفاء القسري عندما يتطلب وجود

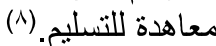

كما احتوت الإتفاقية على عدد من الأحكام المنظمة للتعاون الدولي في مجال التحقيق وإجراءات المات المساعدة القانونية المختلفة،

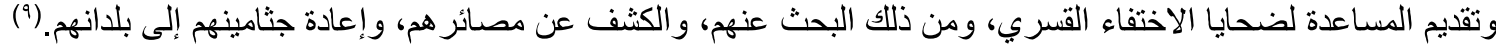

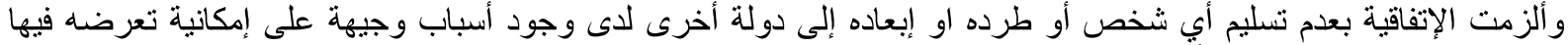

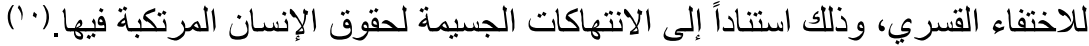

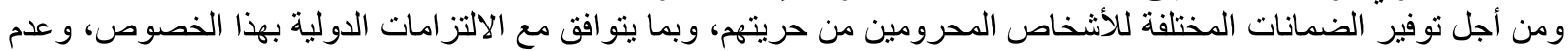

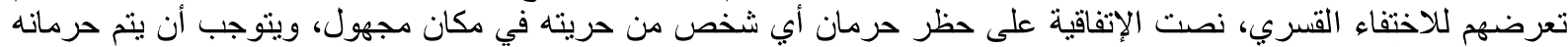

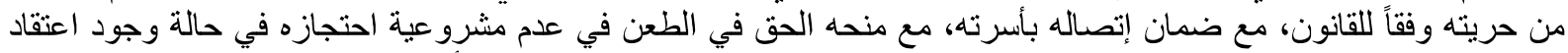

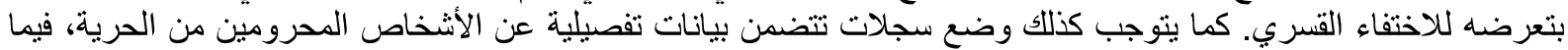

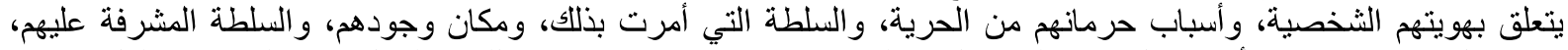
وفي حالة وفاتهم توضيح أسباب الوفاة، والجهة التي نقلت رفاتهم، مع توفير الإمكانية للوصول إلى إلى هذه السجلات، لكل شخص

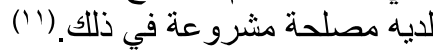

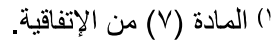

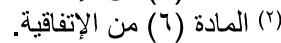

() هاى هاتف مظهر، علي جبار كريدي، صلاح مهدي نصيف، تدابير الحماية الوطنية لجريمة الاختفاء القسري، دراسة مقارنة، مجلة كلية الحقوق،

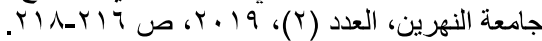

() إتفاقية عدم تقادم جر ائم الحرب والجر ائم ضد الإنسانية لعام 941 (19، متاح على الر ابط الأكتروني: https://www.icrc.org/ar/doc/resources/documents/misc/62sgil.htm

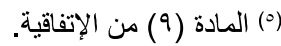

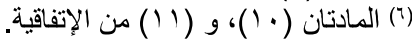

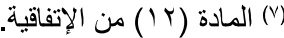

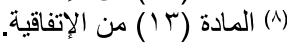

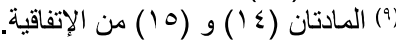

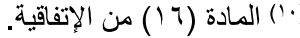

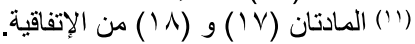


وفي حالة الإفراج عن الثخص المحتجز يتوجب أندان يكون ذلك بطريقة تسمح بالتأكد من تحقق ذلك فعلاً، مع إتخاذ التدابير

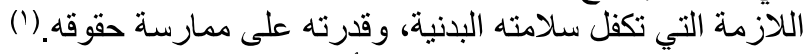

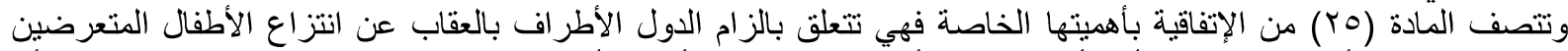

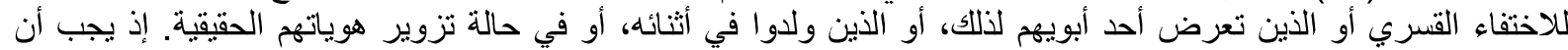

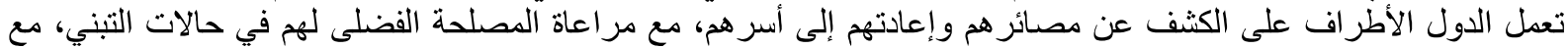

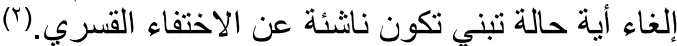
وتتضمن المادة (Tَr) من الإتفاقية واحدة من الضمانات ذات الات الأهمية البالغة بالنسبة لتوفير الحماية الدولية من حالات الاختفاء

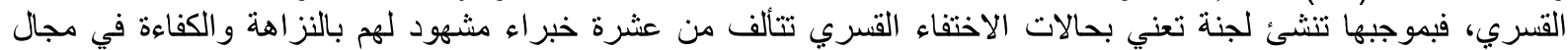

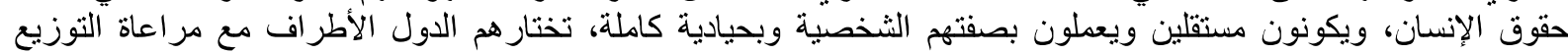

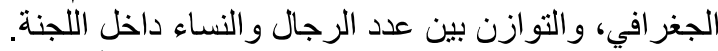

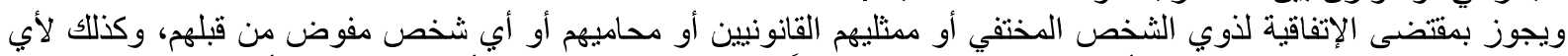

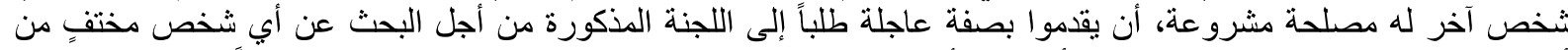

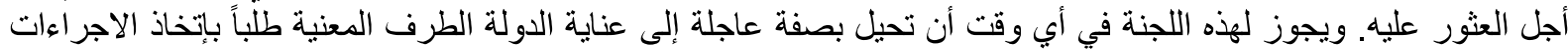

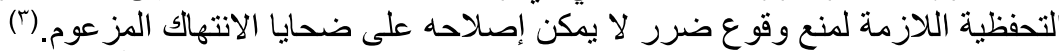

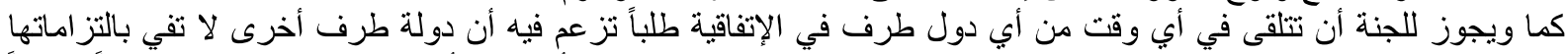

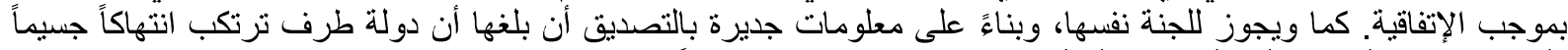

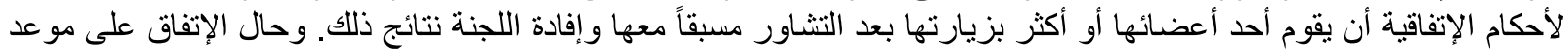
مناسب يتوجب على الإقدانة الدولة الطرف تقديم التسهيلات اللازمة لانجاز الزيارة، وتقدم اللجنة بعد انتهاء الزيارة إلى هذه الدولة

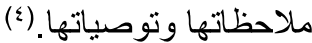

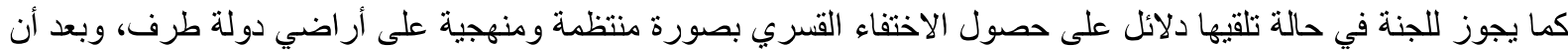

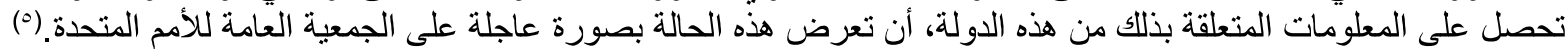

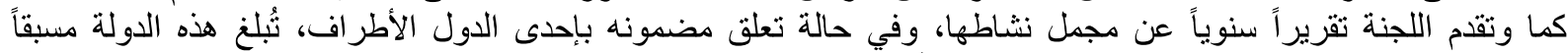

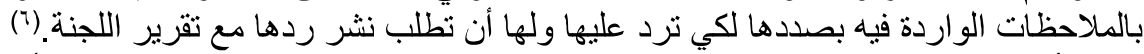

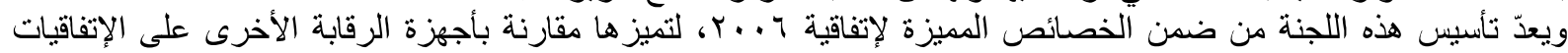

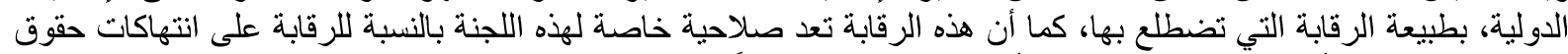

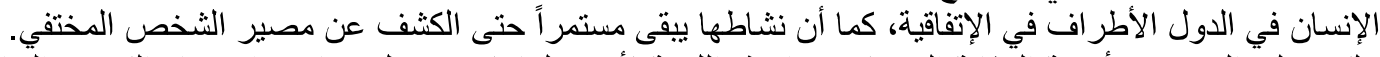

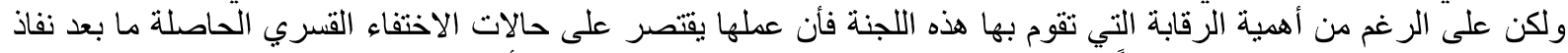

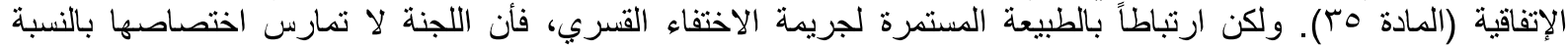

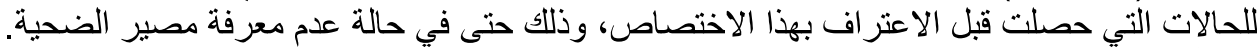

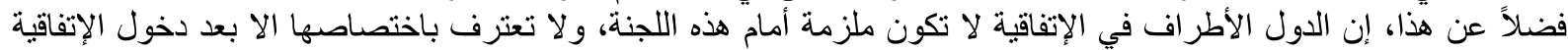

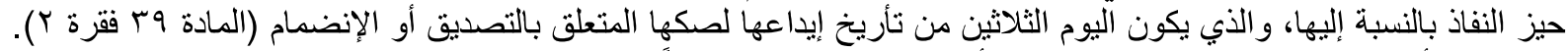

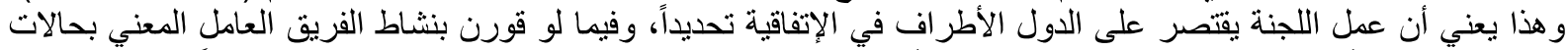

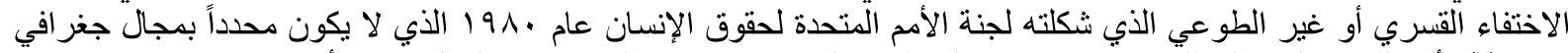

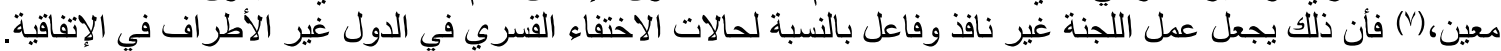
الخاتمة الأتة

توصلنا من خلال بحثنا في موضوع (الاختفاء القسري في القانون الدولي) إلى الاستنتاجات و التوصيات الآتية:

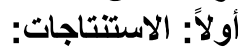

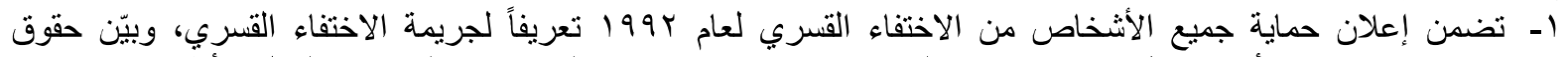

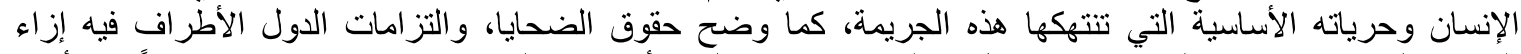

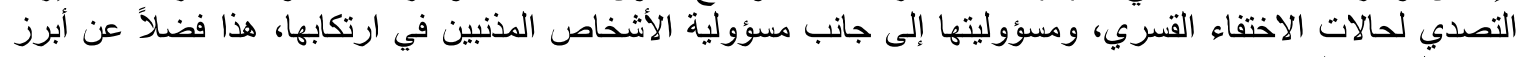
قو اعد التصدي لها.

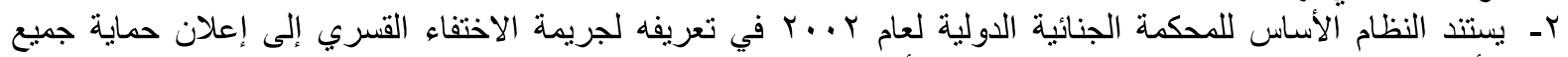

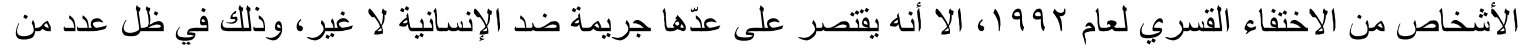

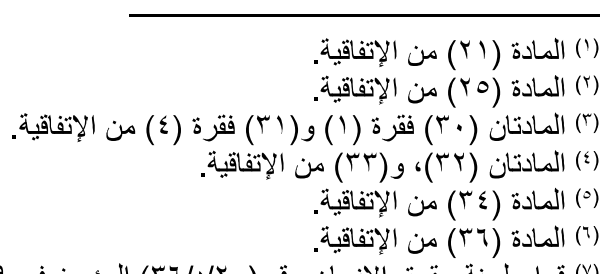

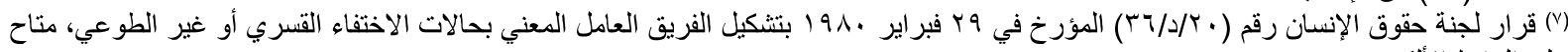
https://www.ohchr.org/Documents/Issues/Disappearances/E-CN.4-RES-1980-20 XXXVI.pdf

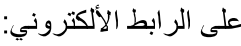


الثروط المتمثلة في ارتكابها في نطاق هجوم ضد المدنيين، سواءً أكان ذلك في وقت السلم أم الحرب، وعلى أن يكون هذا

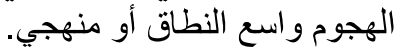

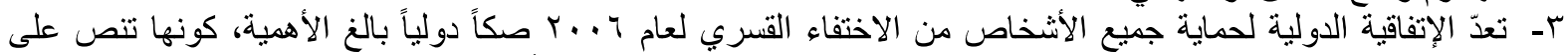

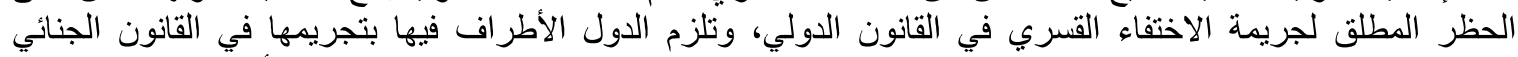

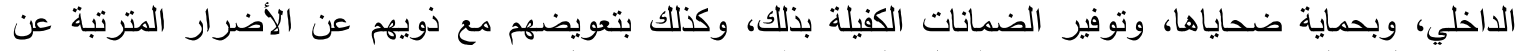

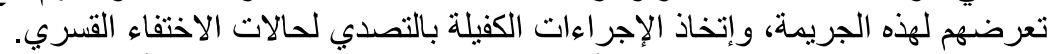

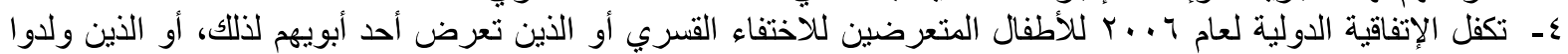

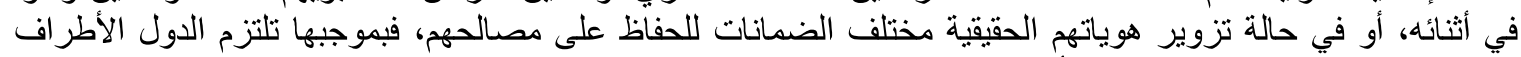

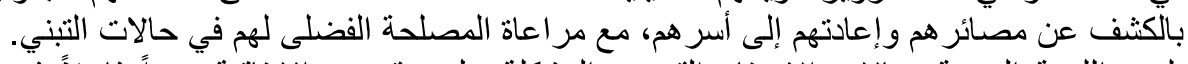

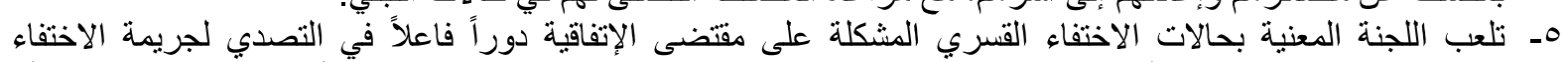

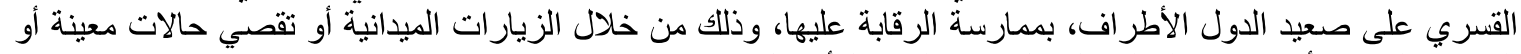

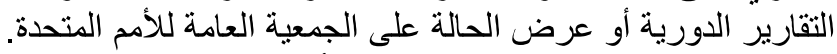

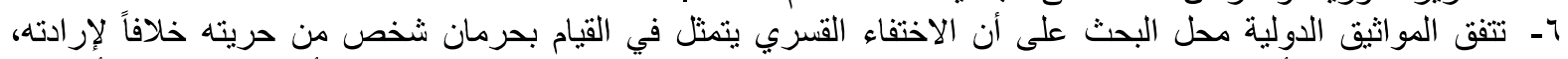

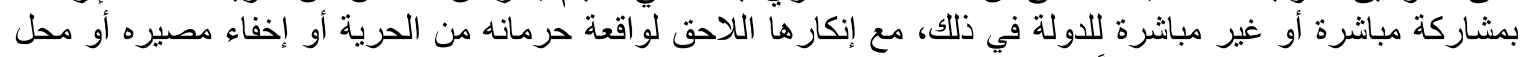
وجوده، ويكون خلال ذلألك محروماً من حمائية القانون. ثانياً: التوصيات:

ا - نوصي بأن تفي جمهورية العراق بالالتزامات النابعة من انضمامها إلى الإتفاقية الدولية لحماية جميع الأثخاص من الإختفاء

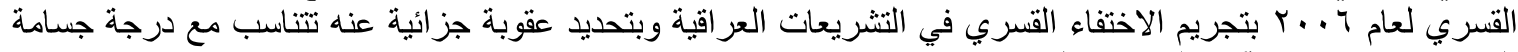
الجريمة وظروفها والآثار المترتبة علئيها.

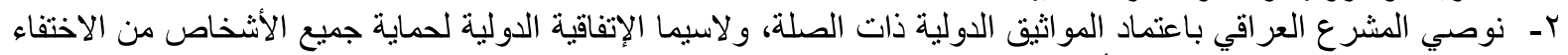

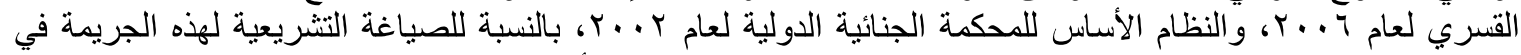

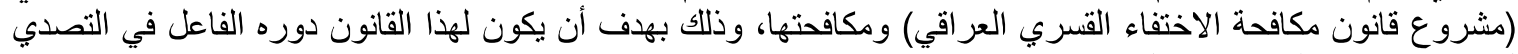

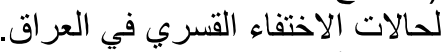

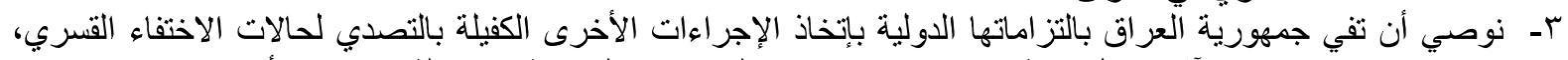

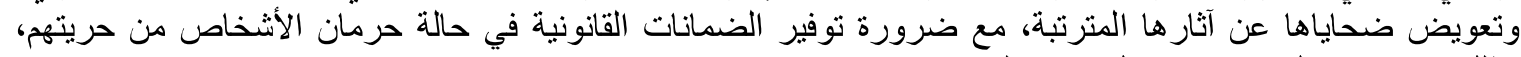
قائمة المصادر

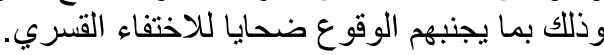

( الكتب: جواد كاظم طر اد الصريفي، الجرائم ضد الإنسانية في ضوء القانون الدولي، دراسة مقارنة، المركز العربي للنشر

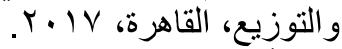

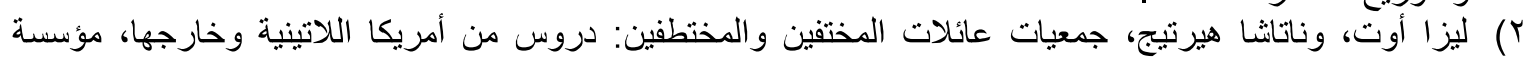

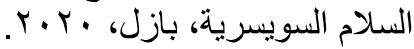

r) محمد عبداللطيف فرج، مواجهة الاختفاء القسري في المواثيق الدولية والتشريع المصري، مطابع الثرطة، مصر، r. 1 .

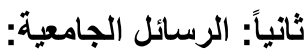

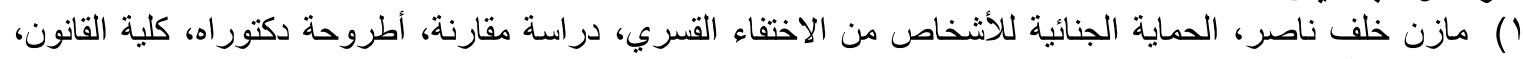

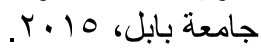

r) نسرين جنادي، الحماية الدولية للأشخاص من الاختفاء القسري، أطروحة دكتوراه، كلية الحقوق، جامعة الجزائر، $r+1 \Lambda-r+1 \mathrm{r}$ ثُالثاً: البحوث:

( ) أحمد تقي فضيل، جريمة الاختفاء القسري وفقاً للنظام الأساس للمحكمة الجنائية الدولية، مجلة واسط للعلوم الإنسانية،

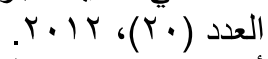

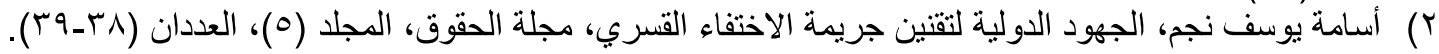

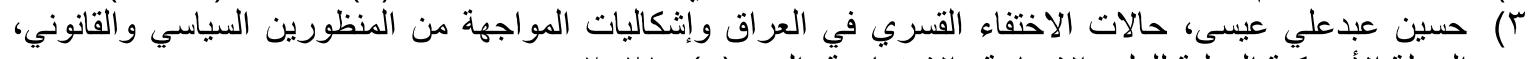

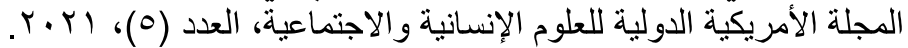

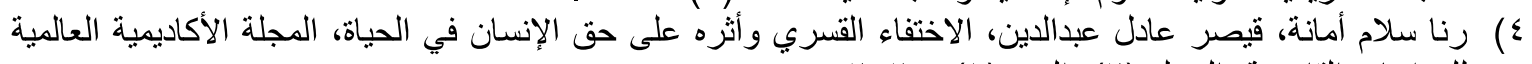

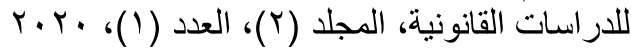

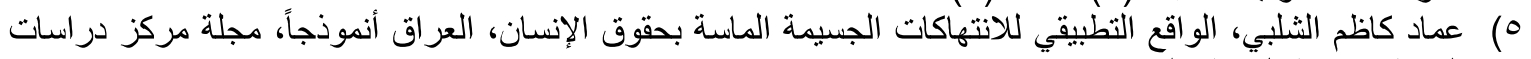

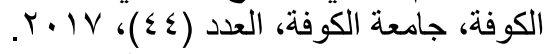

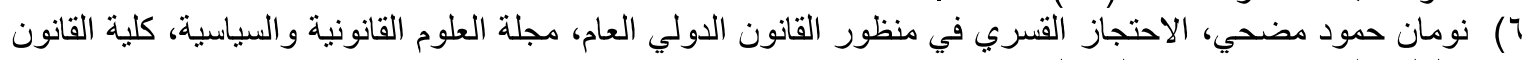

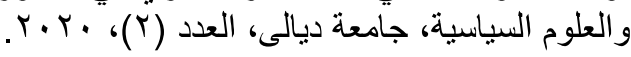


V) هدى هاتف مظهر، علي جبار كريدي، صلاح مهدي نصيف، تدابير الحماية الوطنية لجريمة الاختفاء القسري، دراسة

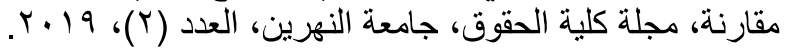

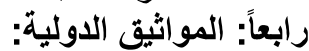

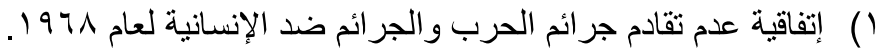

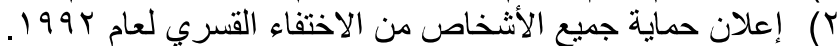

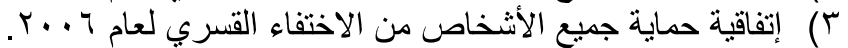

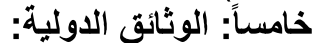

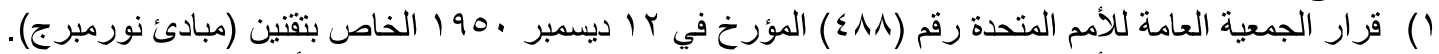

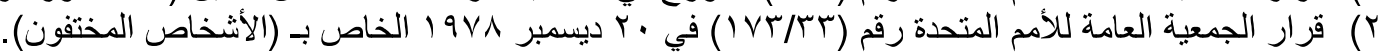

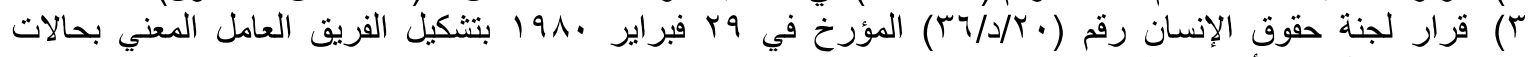
الاختفاء القسري أو غير الطوعي.

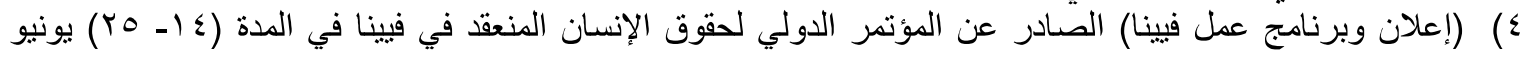
1994

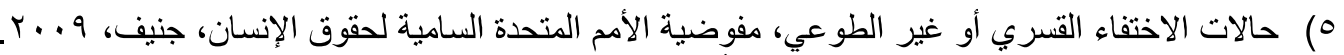

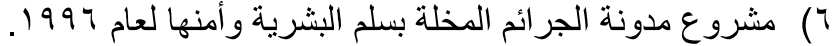

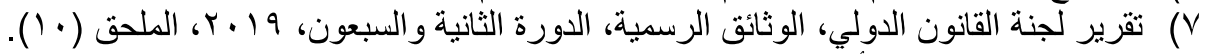

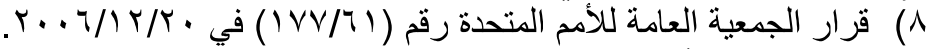

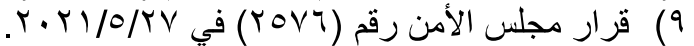
سادساً: النظم الأساسية للمحاكم الجنائية الاولية:

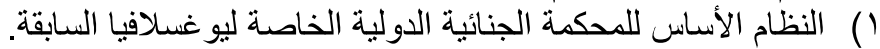

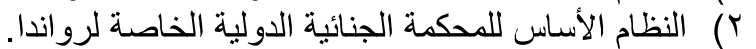

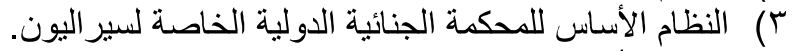

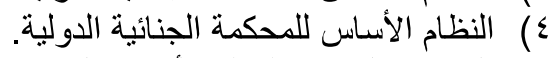

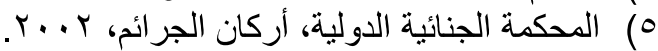

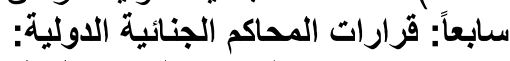

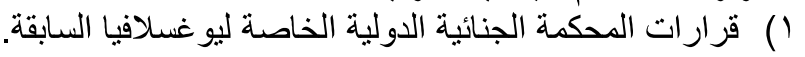

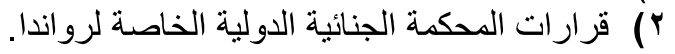

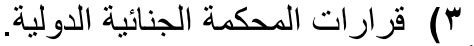

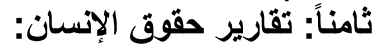
(1) تقرير المفوضية المستقلة لحقوق الإنسان في العراق الخاص بحرية الرأي والتعبير والتظاهر السلمي للمدة من

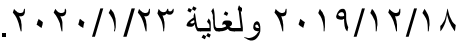

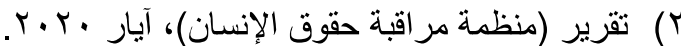

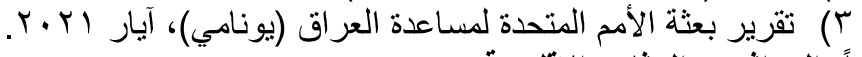
تاسعاً: المواثيق والوثائق الإقليمية:

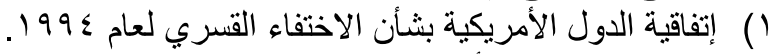

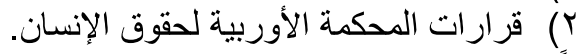

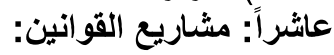

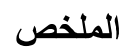
( ) مشروع قانون مكافحة الاختفاء القسري العراقي.

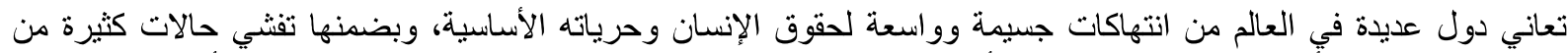

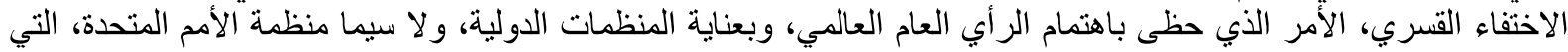

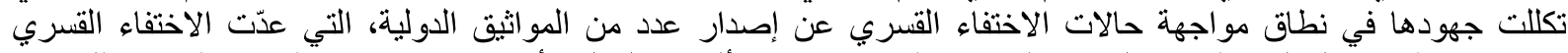

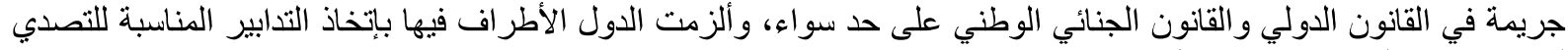
له، وتعويض الضحايا ومعاقبة الجناة.

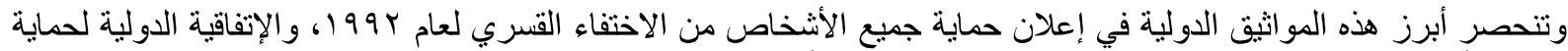

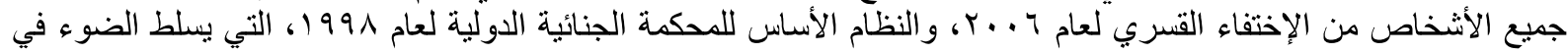

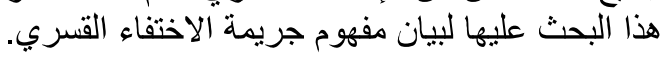

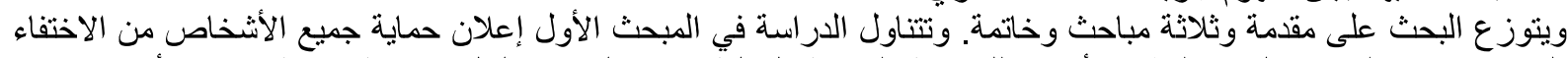

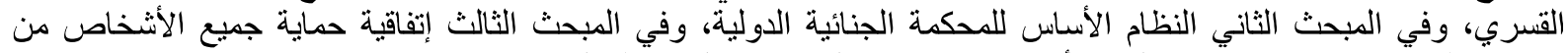

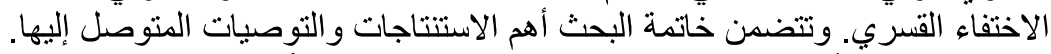

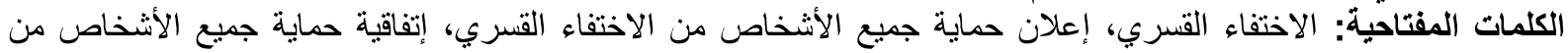

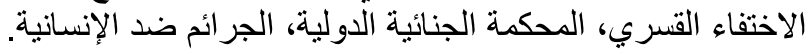




\begin{abstract}
Many countries around the world are suffering from massive and widespread violations of human rights and fundamental freedoms, including the proliferation of numerous cases of enforced disappearance, which has attracted the attention of the world community and international organizations, especially the United Nations, whose efforts have culminated in countering enforced disappearances as a result of the adoption of some international covenants. which considered enforced disappearance a crime in both international and national criminal law, and obliged participating States to take appropriate measures to address this problem, to compensate victims, and punish those responsibly.

The best known of these international Conventions are the Declaration for the Protection of All Persons from Enforced Disappearance of 1992, the International Convention for the Protection of All Persons from Enforced Disappearance of 2006, and the Statute of the International Criminal Court of 1998, which this study examines to explain the concept of enforced disappearance.

The study is divided into an introduction, three chapters, and a conclusion. The first section of the study examines the Declaration on the Protection of All Persons from Enforced Disappearance, the second section deals with the Statute of the International Criminal Court, and the third section deals with the Convention for the Protection of All Persons from Enforced Disappearance. The conclusion of the study includes the most important conclusions and recommendations.

Keywords: Enforced disappearance, Declaration on the Protection of all Persons from Enforced Disappearance, International Convention for the Protection of All Persons from Enforced Disappearance, International Criminal Court, crimes against humanity.
\end{abstract}

